\title{
Quality of Services Based on Intelligent IoT WLAN MAC Protocol Dynamic Real-Time Applications in Smart Cities
}

\author{
Abbas Alnazir, ${ }^{1}$ Rania A. Mokhtar, ${ }^{2}$ Hesham Alhumyani, ${ }^{2}$ Elmustafa Sayed Ali $\mathbb{D}^{1,3}$ \\ Rashid A. Saeed $\left(\mathbb{D},{ }^{2}\right.$ and S. Abdel-khalek ${ }^{4}$ \\ ${ }^{1}$ Department of Electrical Engineering, College of Engineering, Red Sea University, Port Sudan, Sudan \\ ${ }^{2}$ Department of Computer Engineering, College of Computers and Information Technology, Taif University, P.O. Box 11099, \\ Taif 21944, Saudi Arabia \\ ${ }^{3}$ Department of Electronics Engineering, College of Engineering, Sudan University of Science and Technology, \\ Khartoum 1111, Sudan \\ ${ }^{4}$ Department of Mathematics, College of Science, Taif University, P.O. Box 11099, Taif 21944, Saudi Arabia
}

Correspondence should be addressed to Elmustafa Sayed Ali; elmustafasayed@gmail.com

Received 31 July 2021; Accepted 19 October 2021; Published 31 October 2021

Academic Editor: Ahmed Mostafa Khalil

Copyright $(92021$ Abbas Alnazir et al. This is an open access article distributed under the Creative Commons Attribution License, which permits unrestricted use, distribution, and reproduction in any medium, provided the original work is properly cited.

The future directions and challenges for $6 \mathrm{G}$-enabled wireless communication for IoT applications are mainly focused on quality of service (QoS). The selection criteria of mobility management (MM) protocol are mainly the total duration of the delay and packet loss rate during the $\mathrm{MM}$ procedure. This is called intelligent handover $(\mathrm{IH})$ to designate a relay with a minimum delay. To solve the problem of handover, media access control (MAC) protocols are used to provide an intelligent protocol for QoS in real-time application in mobility. Moreover, changing the parameter to find the best protocol for mobile stations in WLAN is a good choice. This paper proposed a new QoS structure for the point coordination function that is based on a new intelligent enhanced distribution coordination function that suites with dynamic real-time applications and services. The paper addresses the distributed coordination function (DCF) with QoS-based intelligent mobility management in stations and other scenarios with enhanced distribution coordination function (EDCF) to find the result of throughput, retransmission attempts, delay, and data droop. In this paper, the remote topology comprises a few remote stations and one base station within the remote LAN. All remote stations are found that each station can distinguish a transmission from any other station, and there is portability within the proposed intelligent framework.

\section{Introduction}

Wireless LAN technology is the most successive edge network for different communication applications, which can provide simple and flexible network connectivity, in addition to the efficient ability of system scalability and deployment. Recently, IoT WLAN had attention to be more deployed to provide many services and be a part of smart city infrastructure to enable multimedia in real-time service applications. The future directions and challenges for 6G-enabled wireless communication for IoT applications are mainly focusing on the quality of services (QoS). In WLAN applications, quality of service (QoS) is considered an important issue in evaluating the performance of real-time services. The technology known as IEEE802.11 MAC provides a suitable mechanism to control the channel access in WLAN [1-3]. The IoT WLAN MAC is depending on two mechanisms, a coordination distributed function (DCF), and an optional point coordination function (PCF). DCF enables distribution of the channel access according to the carrier sense access with collision avoidance (CSMA/CA). PCF is based on the polling approach to provide control channel access.

The concept of MAC protocol is related to the potential improvement in QoS, which relates to several characteristics that must be taken into consideration such as packet loss, 
delay, bandwidth, and data traffic over the network [4]. WLAN provides a data transmission system to enable accessing between independent network and user devices wirelessly. Generally, WLAN is used to provide a communication link between the wired backbone networks to a group of wireless devices, which have independent resources and services. Another concept is micromobility that describes the movement of a mobile node between two attachment points on the same network [5]. Due to device mobility, handover management is required to perform stable communications based on the device locations and WLAN access points. For that, some functions must necessarily have a protocol authorizing the mobility management, citing the transfer of packets, the update of ways or roads, the management of handovers, the support of inactive mobiles, the management of addresses, authentication and security mechanisms, and so on [6-9].

When considering IoT WLAN networks, it was found that the quality of service varies from one application to another, depending on the bandwidth used and the factors related to delay and loss of data. The standard IEEE 802.11 MAC cannot be able to provide an efficient QoS performance in multimedia applications. This is because multimedia requires that MAC serve all transmission frames with the same priority level [10]. Therefore, new technology has been identified with the ability to deal with applications that require high QoS and are known as IEEE 802.11e. An enhanced distributed function (DCF) mechanism is used for IEEE 802.11e to provide QoS prioritization for WLAN applications [11]. This paper proposed a new QoS structure for the point coordination function that is based on a new intelligent enhanced distribution coordination function that suites with dynamic real-time applications and services, for example, smart city-based internet-of-thing (IoT) services, that is, RT surveillances, unmanned transportations and vehicles, smart management system for energy, and city control and monitoring rooms for environmental and security.

The remainder of this paper is organized as follows: Section 2 is discussed on intelligent IoT WLAN MAC QoSrelated work and problematic issues. Section 3 discusses the proposed theoretical model of enhanced distribution coordination function (EDCF). Section 4 is discussed the system-level simulation results and discussions. Finally, the paper is concluded, and the future directions and challenges for 6G-enabled wireless communication with dynamic QoS were given.

\section{Related Works and Motivation}

Tall information rates at the physical layer at versatility have ended up conceivable in remote communication [12]. MAC strategy is considered an improvement for single-channel remote systems in WLAN, which enables the sharing of common radio channels. It provides an effective utilization of the accessible transmission capacity and ensures the fulfillment of QoS prerequisites of both information and real-time applications in portability [13]. Services related to real-time applications, such as those related to video and audio communications, need WLAN with a higher quality of service and better performance.

In [10], it reviewed the concept of IEEE 802.11 as a working group to supplement IEEE 802.11e WLAN, which provides better quality of service (QoS) to multimedia and other real-time applications. The authors also analyzed the IEEE 802.11e and IEEE 802.11 WLAN Intelligent MAC protocols and compare them in terms of QoS performance, latency, throughput, and packet loss. The comparison results show that IEEE 802.11e has outperformed the QoS of IEEE 802.11 in channel allocation and management conditions [14]. However, IEEE 802.11 protocol is found better than IEEE $802.11 \mathrm{e}$ in collision resolution when the network is highly congested.

In [15], it proposed a Markov model to analyze the EDCF performance for IEEE802.11e. The author provides the present extensive performance evaluation for EDCF in terms of throughput and access delay related to the flows in RTS/ CTS mode [16]. Moreover, the study presents the quantitative analysis for the parameters of arbitration interframe space, and contention window (CW), in addition to their effect on QoS.

In [17], the authors proposed and evaluated the enhanced distributed coordination function (EDCF) and compare it with 802.11 original standards. From the evaluation, the authors reviewed that EDCF enables to access channel frames with different priorities. The study also presents the concept of contention-free burst (CFB) [18] and its ability to enable multiple frame transmissions during a single transmission opportunity. The evaluation results show that EDCFS enables different traffic to be provided by differentiated channel access. Moreover, the use of CFB helps improve the performance of EDCF and ensures high WLAN network throughput with acceptable delays. In [19], the authors proposed reviewing the main properties of distribution coordination function (DCF) and point coordination function (PCF) in IEEE802.11 IOT WLAN MAC and showed that the two mechanisms can support better QoS [20].

According to the importance of EDCF for different WLAN based on IEEE802.11 [21], we consider that the EDCF mechanism in IEEE 802.11e enables it to enhance the WLAN QoS, especially for shared wireless media applications. The paper aims to evaluate the performance of EDCF and EDCF protocols in mobility [22]. The paper will study the elementary perceptions and problems of wireless networks that can enhance WLAN quality of service (QoS) and examine various existing Intelligent IoT WLAN MAC protocols of WLAN. In addition, the study will implement and compare efficient mechanisms that can improve the QoS of WLAN. In our study, various parameters will be evaluated for EDCF protocols such as network load, data dropped, and access delay [23].

\section{Intelligent IoT WLAN MAC Layer}

MAC protocol is used to enhance the operation of channel media accessing, which is considered as a logical entity that enables to control and coordinate the system and device 
access to the radio channels [24]. The MAC performs the operations related to frames to handle data traffic between the PHY layer and the wired network. Figure 1 shows the frame of packet format accessed from the MAC to PHY layer [25]. In the frame structure, up to four addresses are required to identify the WLAN access point address. These four fields enable to the registration of the access point addresses in the case of two users sending a packet in WLAN, each with a different access point [26].

In WLAN, all clients are using the same channel for transmission. According to this, the WLAN network standard requires a mechanism that determines how clients can or cannot send to the network. Multiple access mechanism enables to handle this issue. Such a mechanism is known as multiaccess with carrier avoidance (CSMA/CA). CSMA/CA enables client to work together to differ access to the medium using the same wireless channels [27].

\subsection{QoS-Based Intelligent DCF Structure. Carrier-sense} multiple access collision avoidances are based on the multiple access technique used in Ethernet connections that depends on collision detection [28]. In the CSMA mechanism, senders sense the first transmission channel and ensure that is not occupied by any other transmission. This mechanism helps avoid packet collisions with other senders. The mechanism of CSMA collision detection is used in wired Ethernet connections. It enabled to detection of collision occurrence. In wireless communications, the mechanism of collision detection is not possible [29]. The IEEE802.11 releases a standard to enable collision avoidance with a strategy of waiting and sending through shared wireless channels. IoT WLAN clients must ensure that the wireless channels have not been occupied for some time before they transmit their packets. Figure 2 shows the proposed method QoS-based intelligent DCF that propose a waiting and sending mechanism according to the dynamic RT services [30-34].

3.2. QoS-Based PCF Structure. Point coordination function (PCF) is another protocol used as a part of IEEE 802.11 [35]. PCF enables two sensitive packets to allow for the transmission of data with higher priority over high data. The strategy of PCF depends on using the polling procedure that helps manage the free period for the priority over the DCF procedure. In the free period of PCF contention, a single host allows the clients to transmit their sensitive packets [36].

\subsection{Enhanced Distribution Coordination Function (EDCF) for} QoS. This paper proposed a new intelligent enhanced distribution coordination function based new QoS structure for the point coordination function that suites for dynamic realtime applications and services. The EDCF mechanism is provided to supply prioritized QoS by improving the contention-based DCF. EDCF gives separated, conveyed accessing remote media for QoS systems and devices and utilizes diverse user priorities [37]. The EDCF component characterizes four distinctive first-come, first-served (FCFS) lines (see Figure 3), called accesses categories (AC) [38] that give a bolster for the conveyance of activity with user priorities to the QoS systems and devices. Any information bundle from a higher layer at the side of a particular client's need esteem ought to be mapped into comparing AC concurring to Table 1 [39-43]. For the accesses categories, an enhanced variant of the DCF called an enhanced distribution channel accesses function (EDCA) contends for a transmission opportunity (TXOP) [44].

From Figure 3, each AC carries on a virtual node, which it competes for accessing the mediums and then begins its backoff procedure.After detecting the mediums, the virtual node still needs to wait at least for the shortest AIFS period. In EDCF, a modern sort of uncertainty is presented, the arbitraries IFSs (AIFSs), the input of DIFSs in DCFs [45]. All AIFSs are uncertainties interim with subjective duration as follows:

$$
\operatorname{AIFSs}[\mathrm{AC}]=T_{s} x \operatorname{AIFSNs}[\mathrm{AC}]+\mathrm{SIFS},
$$

where AIFSNs[AC] is noted as the arbitrated IFSs and specified by the ACs and the physical structure and the $T_{\mathrm{s}}$ time slot is the length of a slot time (see Figure 4).

The ACS with the lowest AIFSs has the top priority. The values of AIFSs $[\mathrm{ACs}], \mathrm{CW}_{\max }[\mathrm{AC}]$, and $\mathrm{CW}_{\min }[\mathrm{AC}]$, which are denoted as the QoS-based EDCF coefficients, are broadcast by the AP via a beacon frame [46]. The objective of utilizing various contention coefficients for various queues is to assign a low priority category with a lengthier time delay than a high precedence category, so the high precedence category is probably the medium to be accessed prior to the low priority category. An inner collision occurs when more than one ACs finish the back-off time simultaneously. In such a circumstance, a simulated collision handler in each QSTA permits the highest-priority ACs to send their frame, and the others execute a back-off procedure with an enlarged CWs value [47].

\section{Dynamic WLANs Applications Methodology}

Generating a simulation methodology that is corresponding to typical scenarios is one of the severe topics in network simulations. In such scenarios and simulations, the topology of the wireless network contained many network clients and APs (i.e., 20 nodes), an access point station, and a wireless server in the WLAN. The access point is associated with other systems and devices (see Figure 5); it assists as a destination for the flow traffic that is sent from the servers or sources [48]. All APs and clients are distributed in such a way that every node is capable of detecting and sensing the transmitters from any part of the collision domain of the WLAN. The mobility is selected randomly and is defined as the mobility from the trajectory option, which in this thesis, we design the mobility to be inside the range of simulation (the mobility can be seen in the white lines in Figure 5). The scenario in Figure 5 is suited for smart citybased internet-of-thing (IoT) services, that is, city control and monitoring rooms for environmental and security, unmanned transportations and vehicles, RT surveillances, and smart management system for energy. 


\begin{tabular}{|c|c|c|c|c|c|c|c|c|}
\hline $\begin{array}{l}\text { Frame } \\
\text { Control } \\
2 \text { Bytes }\end{array}$ & $\begin{array}{c}\text { Duration } \\
\text { \& ID } \\
2 \text { Bytes }\end{array}$ & $\begin{array}{c}\text { Address } 1 \\
6 \text { Bytes }\end{array}$ & $\begin{array}{c}\text { Address } 2 \\
6 \text { Bytes }\end{array}$ & $\begin{array}{c}\text { Address } 3 \\
6 \text { Bytes }\end{array}$ & $\begin{array}{c}\text { Sequence } \\
\text { Control } \\
2 \text { Bytes }\end{array}$ & $\begin{array}{c}\text { Address } 4 \\
6 \text { Bytes }\end{array}$ & $\begin{array}{c}\text { Frame } \\
\text { Body } \\
0 \text { to } 2312 \\
\text { Bytes }\end{array}$ & $\begin{array}{c}\text { Frame } \\
\text { Check } \\
\text { Sequence } \\
4 \text { Bytes }\end{array}$ \\
\hline
\end{tabular}

FIGURE 1: Frame structure for packet access in MAC Layer.

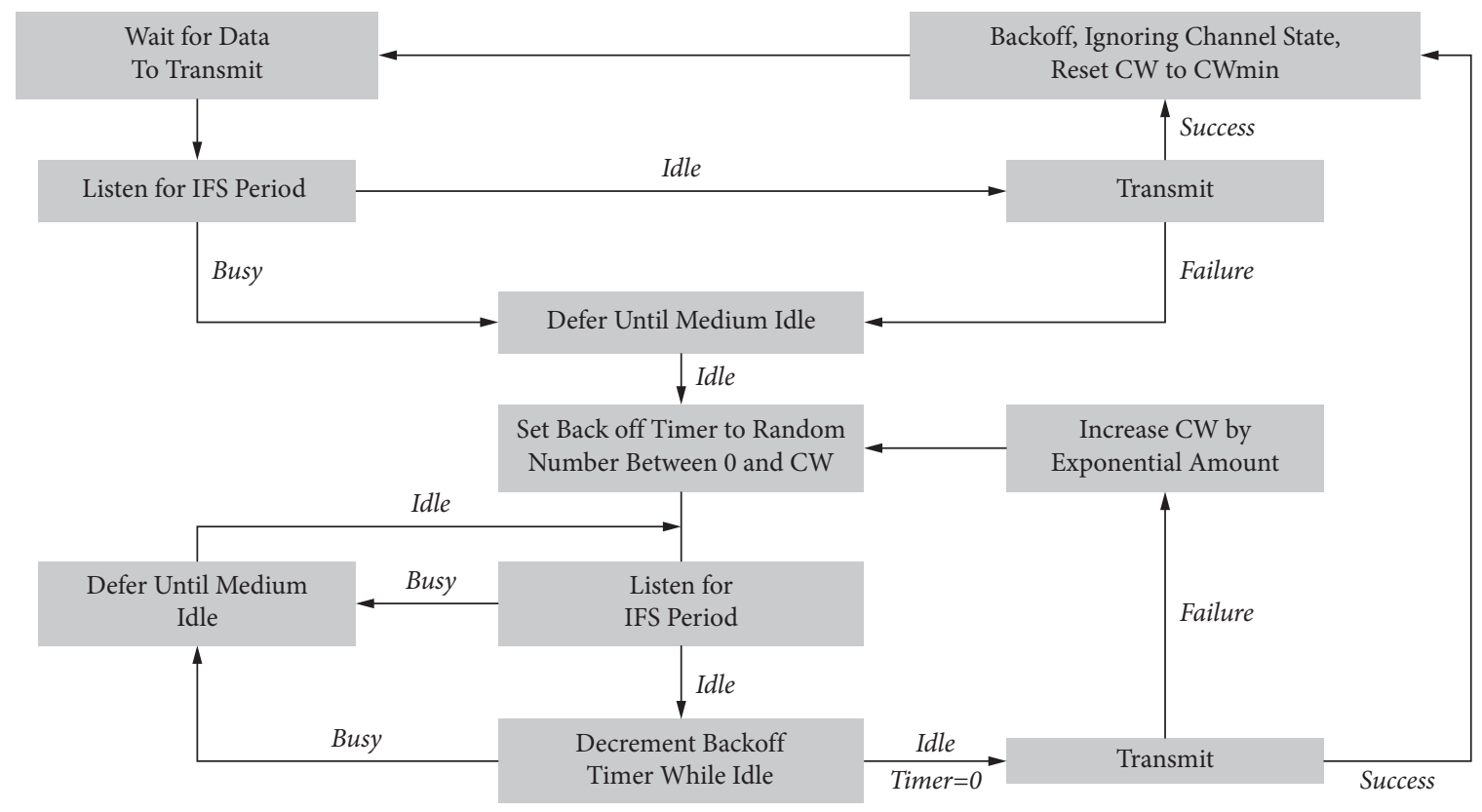

FIgure 2: The proposed QoS-based intelligent DCF for RT IoT applications.

\section{Simulation Methodology and Parameters}

The simulation environments are created by the OPNET ${ }^{\circledR}$ modeler and simulation environment (version 18.9.0) on the Windows ${ }^{\circledR}$ platform (Windows ${ }^{\circledR} 10$ ). For the simulation, there are a few parameters that were configured, that is, the data rate was chosen $11 \mathrm{Mbps}$ for IEEE 802.11e with $54 \mathrm{Mbps}$ data rate for IEEE $802.11 \mathrm{~g}$. Several PHY and MAC parameter values used in our experiments are conferred to IEEE802.11e the typical parameters shown in Table 2 for IEEE802.11b and Table 3 for IEEE802.11g. The MAC and physical parameter values used in IEEE802.11e and IEEE802.11 g are the same except for IEEE 802.11g used extended rate PHY (802.11g) and data rate $54 \mathrm{Mbps}$. We have developed the simulation and run it for two hours in a dual quad-core processor with $1 \mathrm{~GB}$ memory for all scenarios and then benchmarked the achieved results.

For comparison of the performance between EDCF and DCF, two models were developed; medium access in the first model was maintained by EDCF as default, and in the second one, DCF procedure is performed at the data link layer (DLL) as shown in Table 4. Network simulation environment parameters were configured as a benchmark configuration that has been done for both other models. Complete conditions were stated in Tables 2 and 3 show the $\mathrm{PHY}$ and MAC parameters configurations utilized in simulation. The network evaluation for performance is modeled by evaluating both models one by one in the OPNET $^{\circledR}$ simulation tool, and then the achieved results are compared.

In the EDCF case, the four traffics scenarios and classes have been applied to the data link layer from upper layers, which are conforming to ACs-0, ACs-1, ACs-2, and ACs-3, respectively [48] to assist the efficiency of the new proposed algorithm, which provide differential services that are mandatory for real-time (RT) applications. In the case of DCFs, it is not mandatory to offer differential services, which leads to no access class provisioning being needed. As a result, various applications have been configured using the profile applications for the model (i.e., EDCF procedure) for various access classes. In the first application, we named data, while inside, there were applications referred to database, e-mail, FTTP, and HTTP; in the next application, we used the voice application; and in the last application, we used video conference in high resolution. Details are shown in Table 4.

With the configuration application profile, client profiles were modeled and configured by using the three applications/scenarios. In the development of scenarios, 20 nodes were configured to utilize the network administration services chaotically. During the simulation running, we observed that all traffic data have the growth to plot the whole 


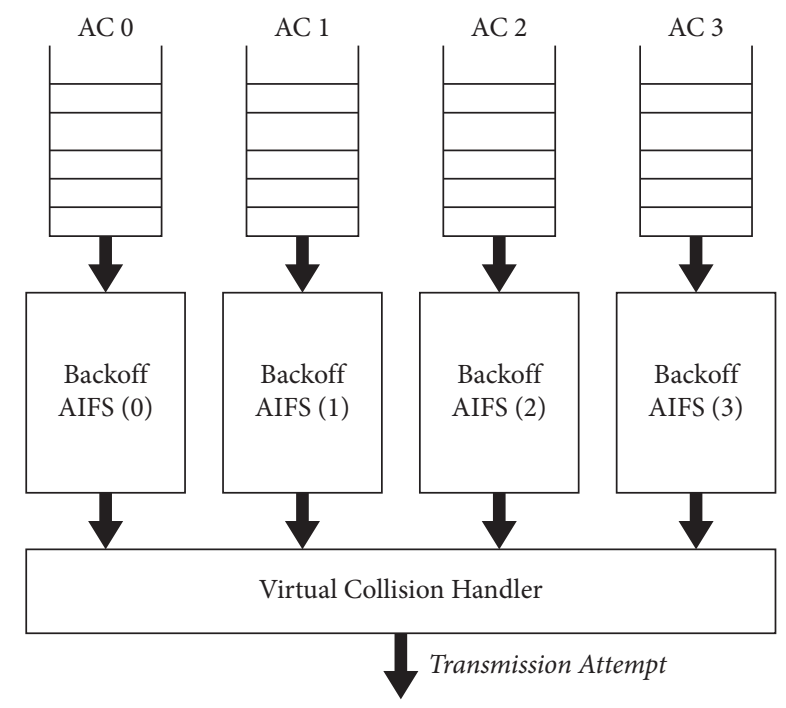

FIgURE 3: Four AC transmission queue implementation models.

network activities in terms of the random number of packets exchanged per time unit. In EDCF, we change the point coordination function (PCF) and hybrid coordination function (HCF) by default to enable them after inserting the value of access category in all applications as shown in Table 5.

\section{Evaluation Results and Discussion}

The results have been generated using $\mathrm{OPNET}^{\circledR}{ }^{\circledR}$ simulation: first, we had identified IoT scenario for smart cities in Figure 5, and then the parameters have been identified as well. In phase 3, the proposed intelligent MAC protocol has been applied and implemented in the OPNET ${ }^{\circledR}$. In phase 4 , QoS data have been collected by simulating for some realtime traffics. In phase 5 , results have been illustrated using MATLAB $2020^{\circledR}$. The purpose of this part is to review and analyze the test and simulation results conducted. A detailed analysis is given here to benchmark the WLAN, EDCF, and DCF behaviors and performance in mobility for different scenarios based on WLAN approaches. The result presents in throughput, media access delay, data drop, and retransmission attempt for data, voice, and video, where the data refer to e-mail, FTTP, and HTTP.

6.1. Performance Analyses for IoT-Based IEEE 802.11e. From the simulation results, in Figure 6, it is shown that the data rate for DCF and EDCF in mobility because of general EDCF does not add priority to data. For data retransmission attempt, it is shown in Figure 7 DCF is better than EDCF for data retransmission in mobility scenario.In the first three minutes, the data retransmission attempt was shorter than others that because the back-off number was smaller (i.e., data drop) in the nodes. One can notice that there are slight variations between EDCF and DCF procedures in terms of retransmission attempts.

This little contrast suggests in general that the retransmission endeavors made in DCF conventions could be a bit lesser than EDCF protocol in portability. Figure 8 shows that for the initial simulation momentthe MAC layer delay for DCF and EDCF functions increases equally, and then afterward,DCF grieves to be less delay than EDCF. . The increment within the intelligent IoT WLAN MAC layer accesses delay for each protocol is because of the increment within the hop number contending to get accesses of media. As shown in Figure 9, the data drop is increased gradually because of the high data transmitted. However, there is no big difference between them; it is better in the end EDCF.

For the voice scenario, as observed from Figure 10, the throughput of EDCF is higher than DCF, and this is due to the contention window of the voicein EDCF protocol is longer than in DCF; the throughput of voice in EDCF protocol reaches $24 \mathrm{kbps}$. The result showed a higher retransmission attempts of EDCF than DCF because of the high throughput of voice in EDCF and data drop as we will see in Figure 11, in the first three minutes, there were no the retransmission attempts, but after that, it isincreased dramatically in EDCF, the EDCF protocol retransmission attempts reach approximate 1.2 packets per second.

Moreover, Figure 12 shows that the delay metric in intelligent IoT WLAN MAC layer access for DCF is higher than EDCF. The high delay in DCF media accessdue tohigh number of nodes thta do not have priority to use long contention window (unlike EDCF with long CW). The EDCF protocol delay reachedupto 10 packets per second. For voice data drop, Figure 13 shows that the high data drop in the voice of EDCF is more than DCF, not only because the high throughput of voice in EDCF is greater than DCF but also because the differential services that can offer the prioritybased method to handle several data types, but it is clear that the retransmission attempts is also high in voice in EDCF. The data drop using the EDCF protocol in voice reach approximately $62 \mathrm{kbps}$.

For the video scenario, Figure 14 shows that the throughput of the DCF is lesser than EDCF because the EDCF adds the contention window that gets big priority to video, which makes the throughput high than DCF. The throughput of EDCF can reach approximately $0.5 \mathrm{Mbps}$. The observation from Figure 15 is that the retransmission attempt in the video is high for EDCF with the difference of more than 0.05 packets in retransmission attempt because the big data dropped for EDCF. The retransmission attempts for EDCF in the video reach approximately 0.51 packets per second.

Moreover, one can notice that Figure 16 shows the intelligent IoT WLAN MAC layer delay for both DCF and EDCF, where the EDCF is less than DCF, because of the priority of EDCF; this means EDCF is better than DCF in media access delay. The EDCF protocol can reach approximately 0.42 packets per second. Figure 17 shows that after simulation time of 120 secs, the drop data in EDCF increases rapidly, due to the differential service behavior of EDCF, which provides the priority-based method to handle several data types. DCF is lower dropped data when it compares to EDCF. The data drops for the EDCF protocol in video approximately reached 45 kbps. 
TABLE 1: AC and TXOP access class details.

\begin{tabular}{lcc}
\hline TXOP & AC & Description \\
\hline 1 & 0 & Backgrounds \\
2 & 0 & Standards \\
0 & 1 & Best efforts \\
3 & 1 & Exceptional efforts \\
4 & 2 & Multimedia streaming (MMS) \\
5 & 2 & Multimedia interactives (MMI) \\
6 & 3 & Voice interactives (VI) \\
7 & 3 & Unused \\
\hline
\end{tabular}

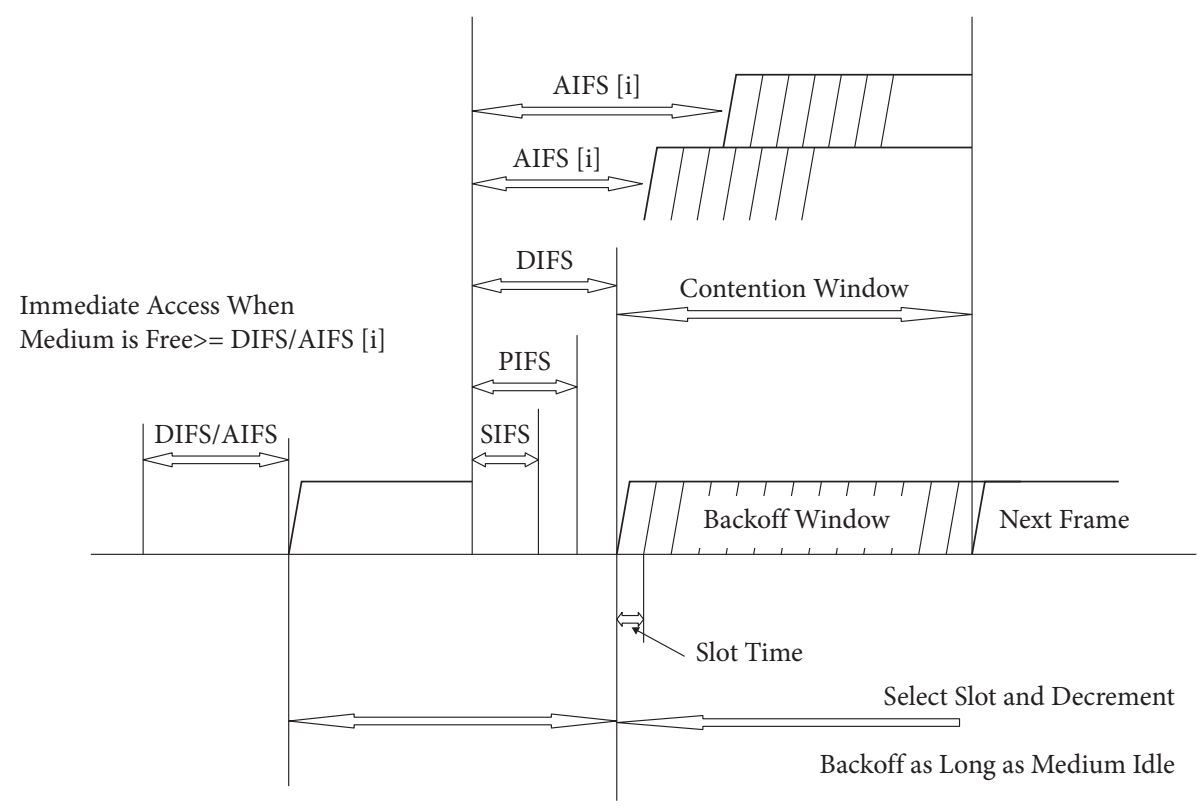

FIGURE 4: The timing relationship of EDCF.

6.2. Performance Analyses for IEEE 802.11g. In such a case, we compare the real-time application of IEEE 802.11 g-stander for $54 \mathrm{Mbps}$ data rate for DCF and EDCF to find the best protocol for quality of service in WLAN in mobility. In the results discussed, the efficiency, data rate, retransmission attempt, medium accesses delays, and dropped of data for voice and video conference only, while we left the pure data as one can see that, no change have been observed for data in EDCF. It observes from Figure 18 that the data rate and capacity of EDCF and DCF are starting as a high capacity for three minutes EDCF degradation; EDCF reaches $100 \mathrm{kbps}$.

As shown in Figure 19, the high retransmission for EDCF than DCF because the high data dropped for EDCF as we will see in data dropped for voice; the retransmission attempts for EDCF protocol reach approximately 2.2 packets per second. Figure 20 shows that media access delay for voice for the EDCF which is found the delay less than DCF, this means EDCF is better than DCF in medium accessed delay for RT voice. The medium accesses delays for EDCF protocol in voice went upto 0.38 packets per second.It can be observed from Figure 21 that the data dropped for EDCF is higher than DCF in the voice because of the service differentiation, which provides the priority; the data drop for voice reach approximately $110 \mathrm{kbps}$, the reason forthat the EDCF shows less performance compared to DCF in mobility for IEEE $802.11 \mathrm{~g}$. This degradation in EDCF performance is due to the degradedof the throughput.

It has been noticed from Figure 22 that for the first two minutes, there is the same throughput for DCF and EDCF; after that, the EDCF has comparatively increased throughput than DCF because of the high priority for video. Therefore, the results are better with EDCF; the EDCF protocol for video reaches approximately $1.8 \mathrm{Mbps}$. From Figure 23 that retransmission attempt packets per second for DCF is fairly more than EDCF, the video retransmission attempts for EDCF protocol approximately reach 0.73 packets per second. Intelligent IoT WLAN MAC accesses delays from Figure 24, the initial of simulation, the MAC access have delays for the two functions i.e., DCF and EDCF, where the increasessimilarly for both, and after awhile, DCFs packets suffer from delays to be more than EDCF.

The increment within the medium-get-to-delay (MGD) for the two models and scenarios is because of the extended and increment of the number of nodes hop in the network competing to access the medium; the media access delay for video in EDCF protocol reaches approximately 0.11 packet per seconds. In Figure 25, the 


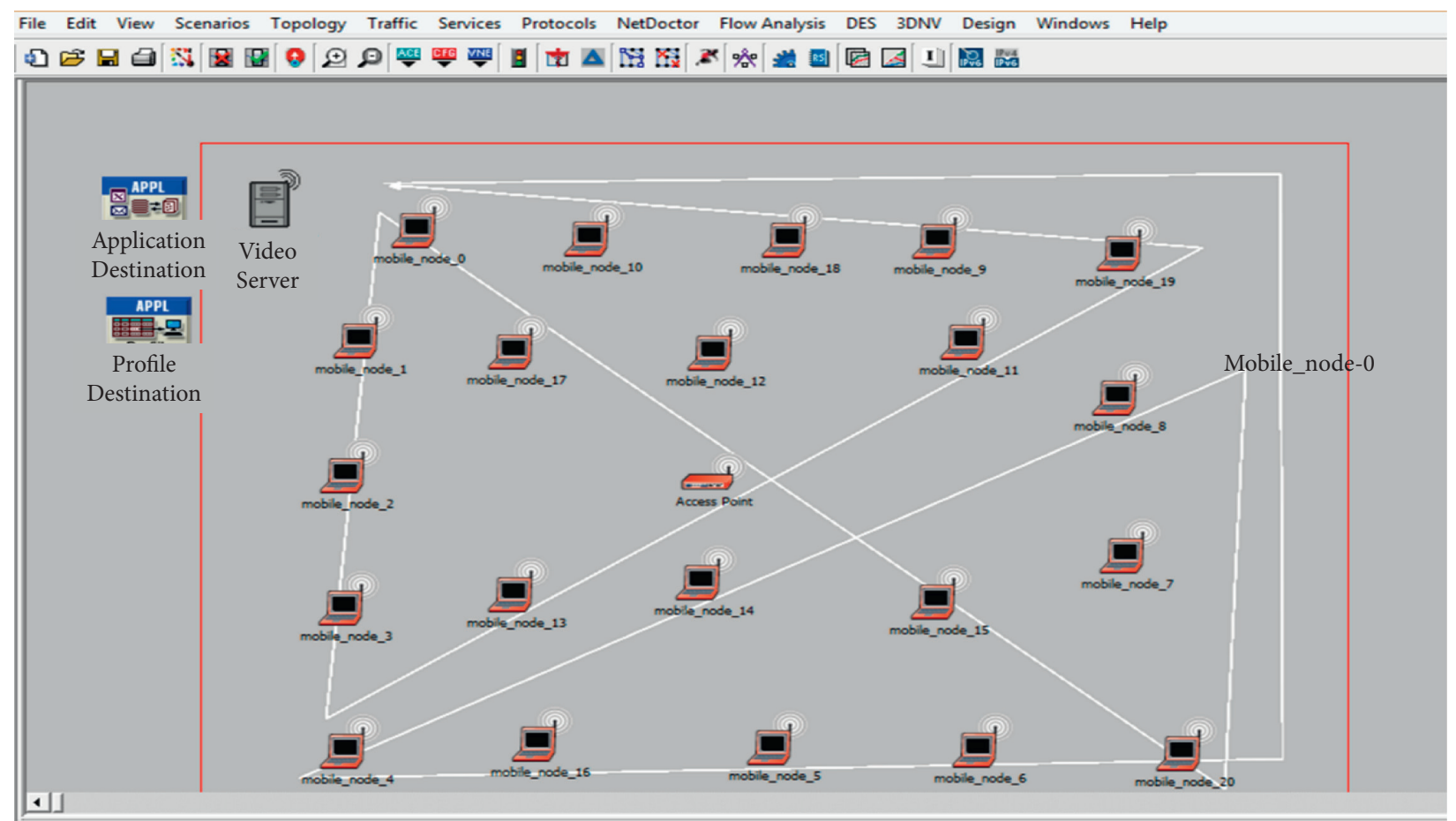

FIgURE 5: The IoT WLAN network model with intelligent mobility scenario.

TABLE 2: PHY and intelligent IoT WLAN MAC coefficients that utilized in the simulation configurations for all scenarios.

\begin{tabular}{lc}
\hline Attribute & Values \\
\hline Physical features & DS \\
Data rates & $11 \mathrm{Mbps}$ \\
Transmit powers & $5 \mathrm{MW}$ \\
Buffer sizes & 256,000 bits \\
BSSs identifiers & Autoassign \\
Channels configurations & Autoassign \\
Roaming capabilities & Enabled \\
AP beacon interval (sec) & $2 \mathrm{MW}$ \\
Processing of large packets & Drops \\
\hline
\end{tabular}

TABLE 3: PHY and MAC parameters configurations utilized in the simulation for IEEE802.11 g.

\begin{tabular}{lc}
\hline Attribute & Value \\
\hline Characteristics of the PHY layer & Extended rate PHY (802.11g) \\
Data rates & $54 \mathrm{Mbps}$ \\
Transmit powers & $100 \mathrm{MW}$ \\
Buffer sizes & 256,000 \\
BSSs identifiers & Autoassign \\
Channels configuration & Autoassign \\
Roaming capabilities & Enabled \\
AP beacons intervals & $5 \mathrm{~ms}$ \\
Processing of large packets & Drops \\
\hline
\end{tabular}

data dropped for DCF and EDCF; the data drop for DCF is increasing more than EDCF because the differential services that implement the priority feature and algorithm to handle several numbers of data types and high throughput/capacity/data rate for EDCF; the video data drop for the EDCF protocol reach approximately $17 \mathrm{kbps}$. As overall performance output, the results from thecollected data were aimed to find the best protocol for 
TABle 4: Access class matching to the applications.

\begin{tabular}{lcc}
\hline Access classes & Applications configuration & Description \\
\hline AC $(0)$ & HTTPS (light-weight) & Backgrounds \\
AC (1) & Login remotely (heavy-weight) & Excellent efforts (EE) \\
AC (2) & Video conferencing & Interactive multimedia (IMM) \\
AC (3) & Voice over IP & Interactive voices (IV) \\
\hline
\end{tabular}

TABle 5: The parameters for the access category.

\begin{tabular}{lcccc}
\hline Priority & AC & CW $_{\min }$ & CW $_{\max }$ & AIFSN \\
\hline 0 & Voice & 7 & 15 & 2 \\
1 & Video & 15 & 31 & 2 \\
2 & Best effort & 31 & 1,023 & 3 \\
3 & Background & 31 & 1,023 & 7 \\
\hline
\end{tabular}

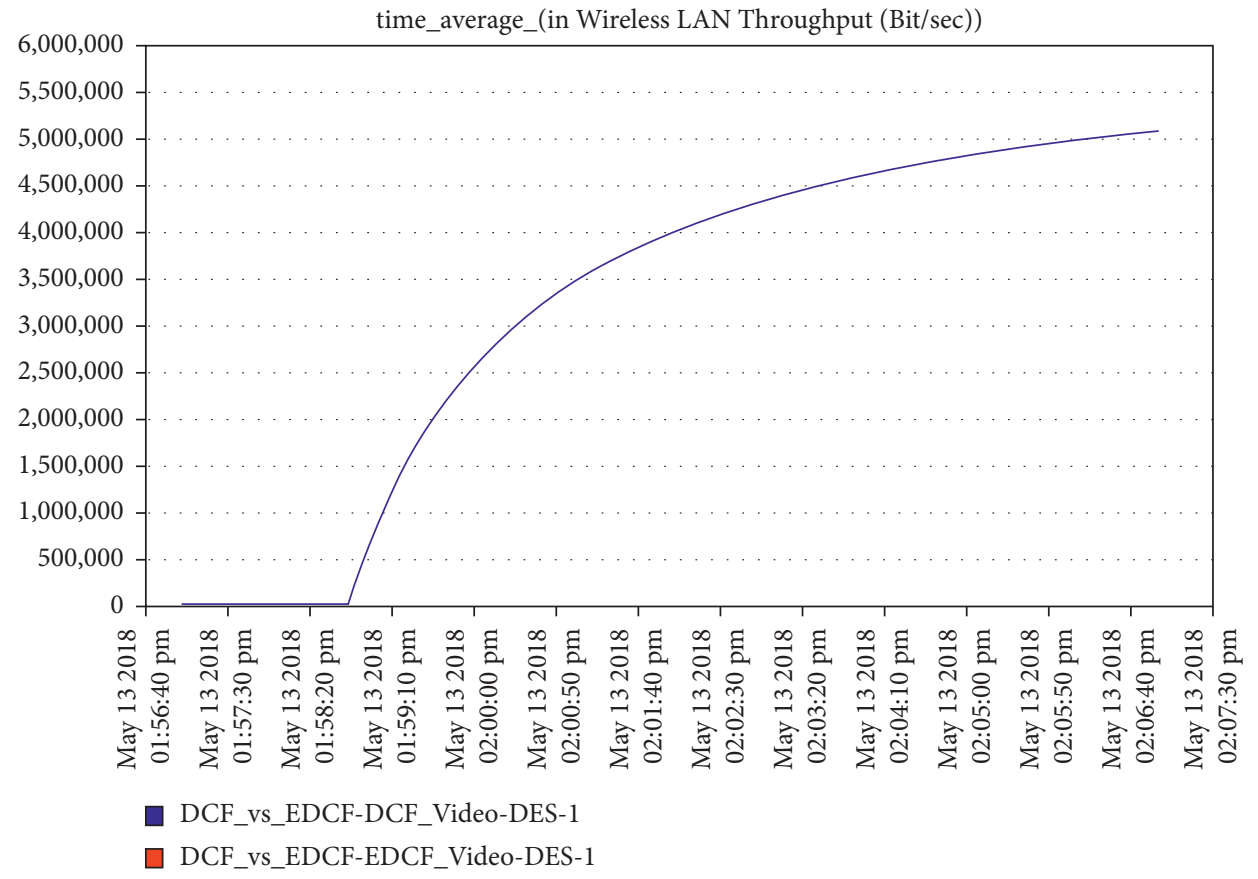

Figure 6: Data throughput in mobility.

IEEE $8021.11 \mathrm{~b}$ and $g$ thatguaranteed QoSin mobility scenario. We noticedthat the throughput metrics for real-time application in EDCF was better thanDCF in IEEE $8021.11 \mathrm{~b}$ standard. That means, the EDCF is appropriate forreal-time applications i.e., voice and video conference.IEEE8021.11g showed that there different performancesfor voice and video throughputs; however in overall the EDCF was the more appropriatedthan DCF for real-time application in QoS in mobility. 


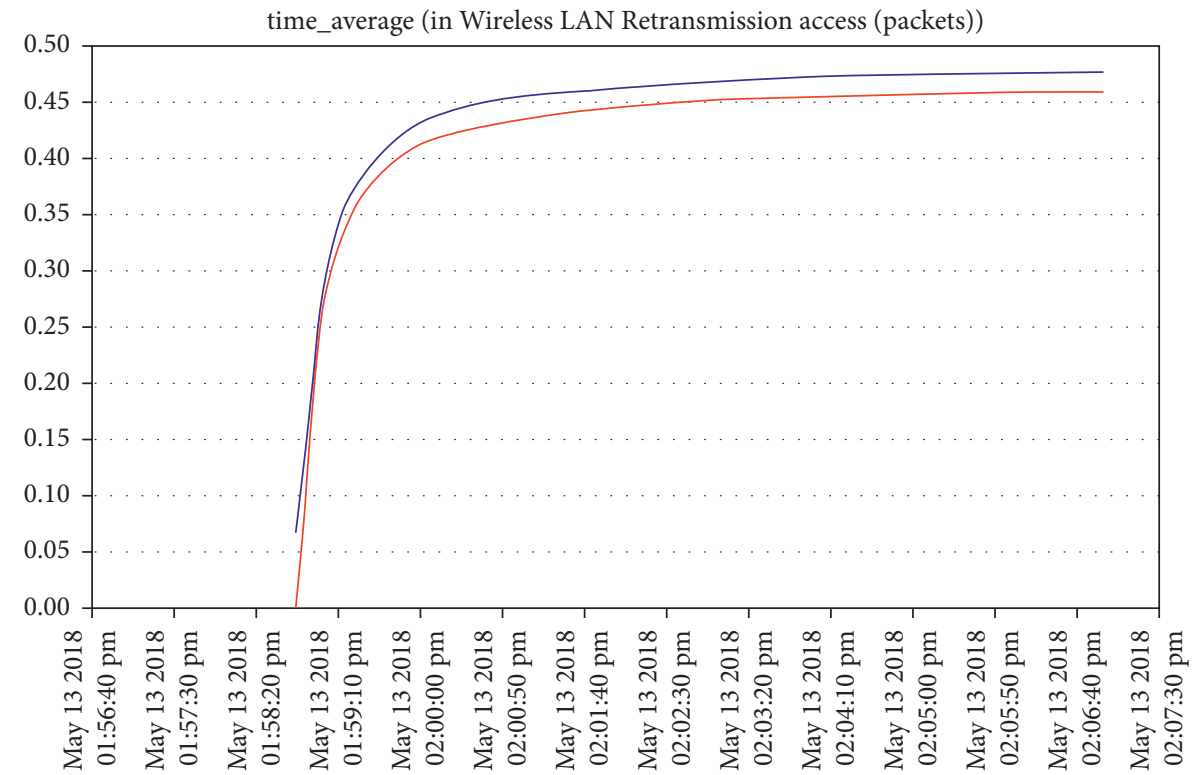

DCF_vs_EDCF-DCF_Voice-DES-1

DCF_vs_EDCF-EDCF_Voice-DES-1

FIgURe 7: Data retransmission attempts in mobility.

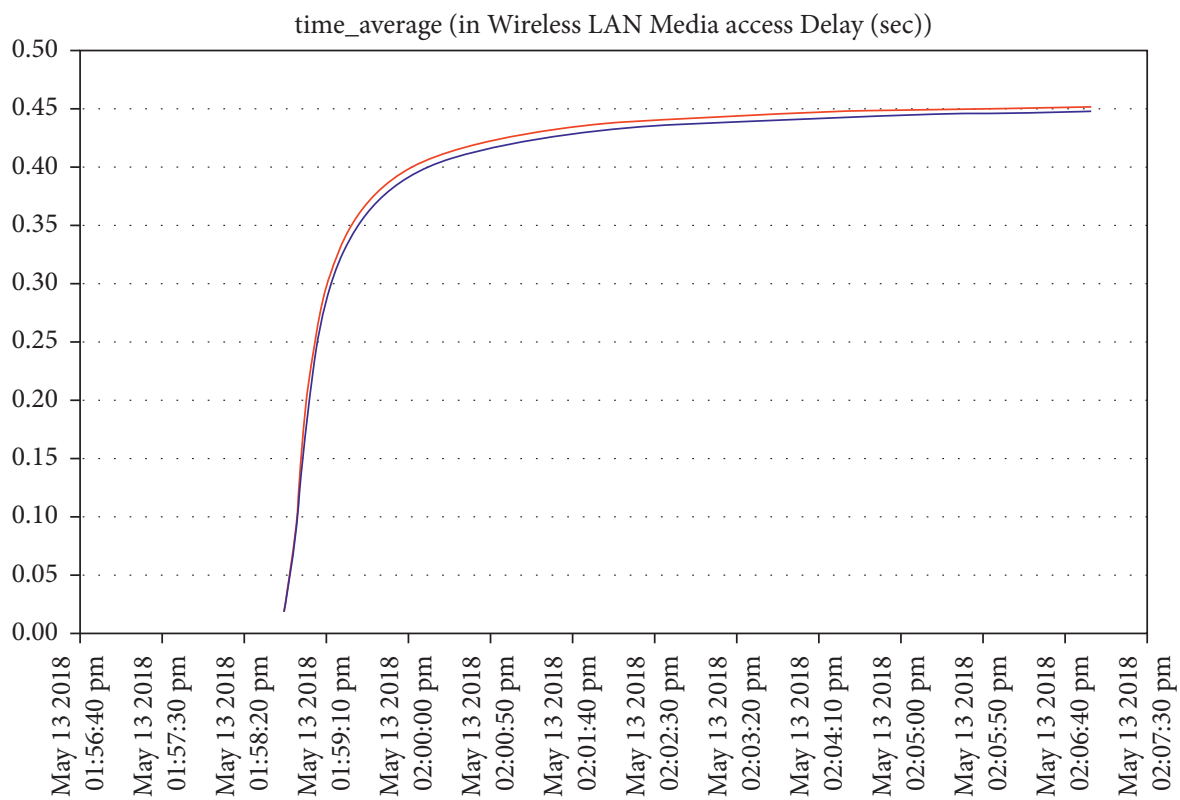

口 DCF_vs_EDCF-DCF_Voice-DES-1

$\square$ DCF_vs_EDCF-EDCF_Voice-DES- 1

Figure 8: Data media access delay in mobility. 


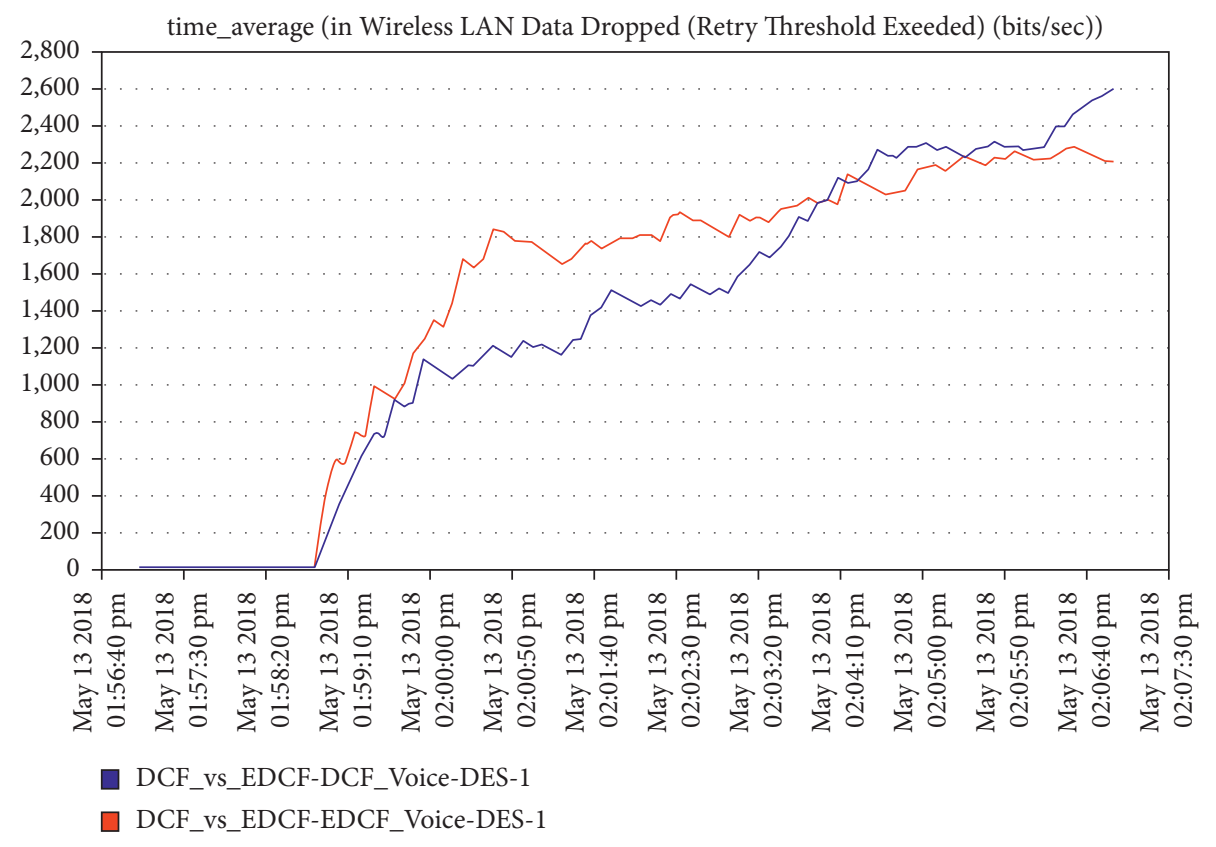

Figure 9: Data dropped.

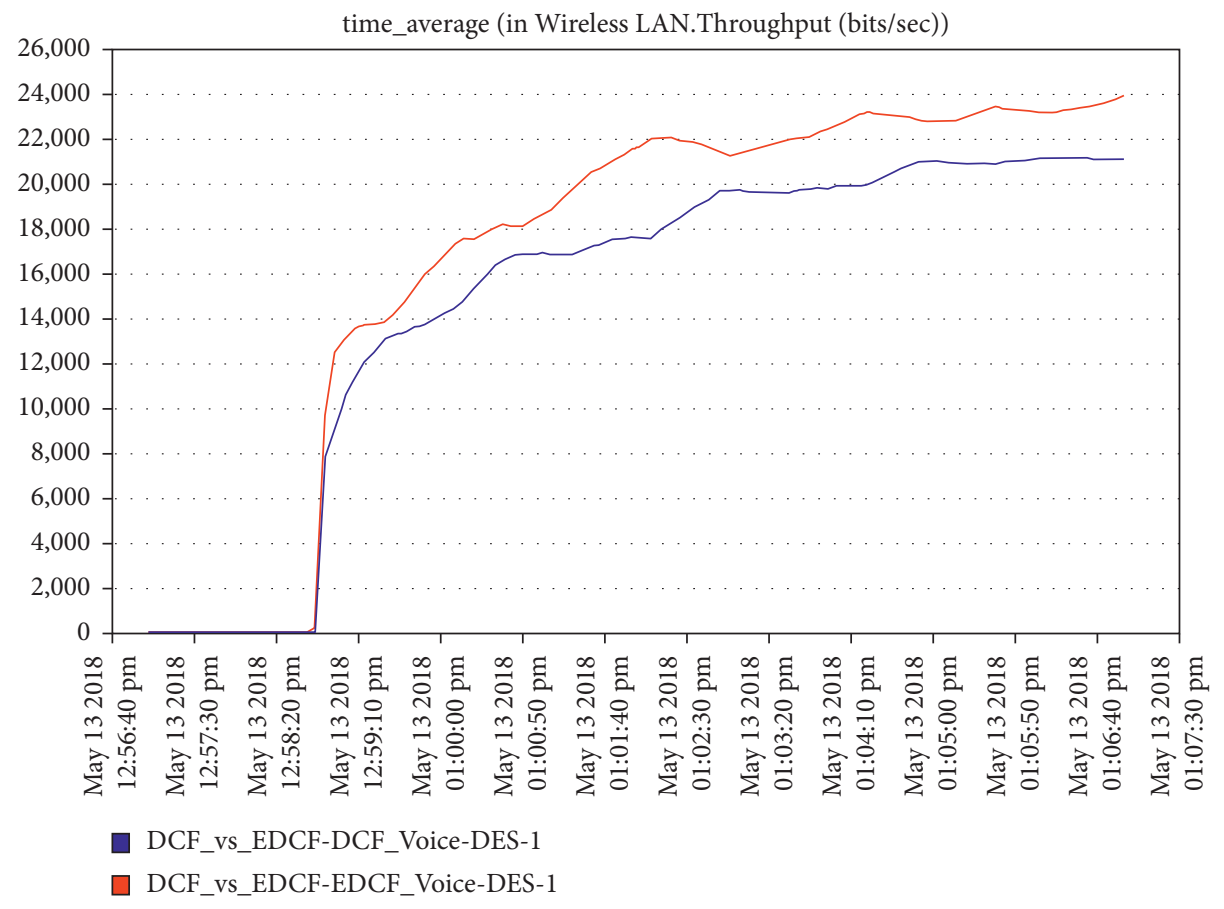

FIgURE 10: Throughput for voice. 


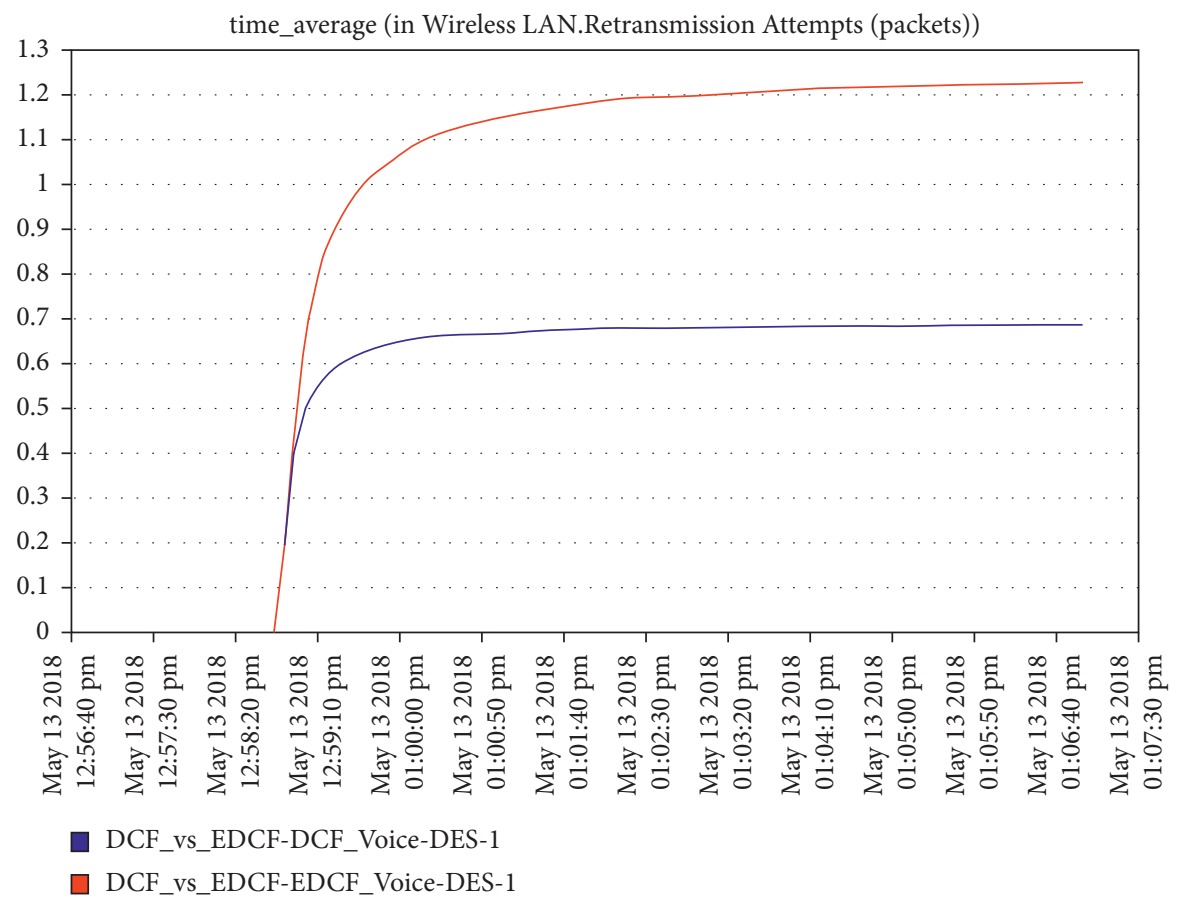

FIgURE 11: Retransmission attempt for voice in mobility.

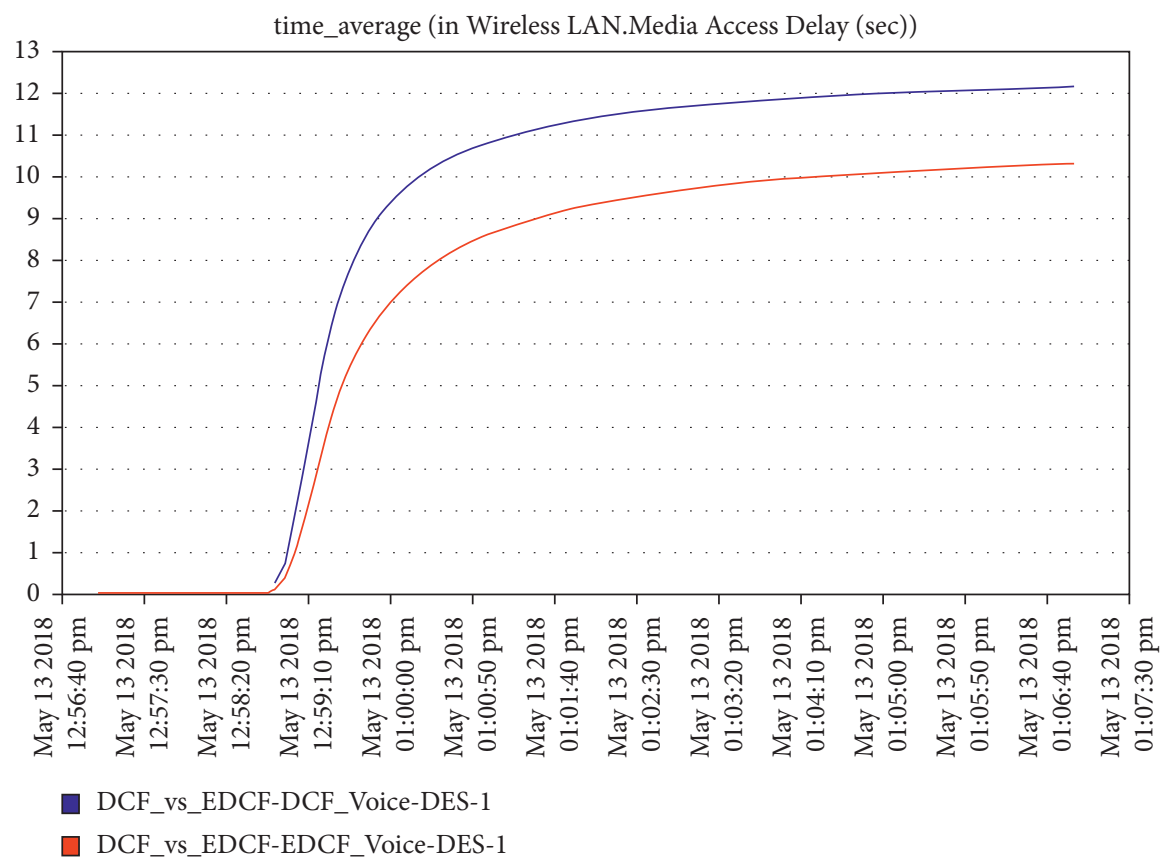

FIgURE 12: Media access delay for voice in mobility. 


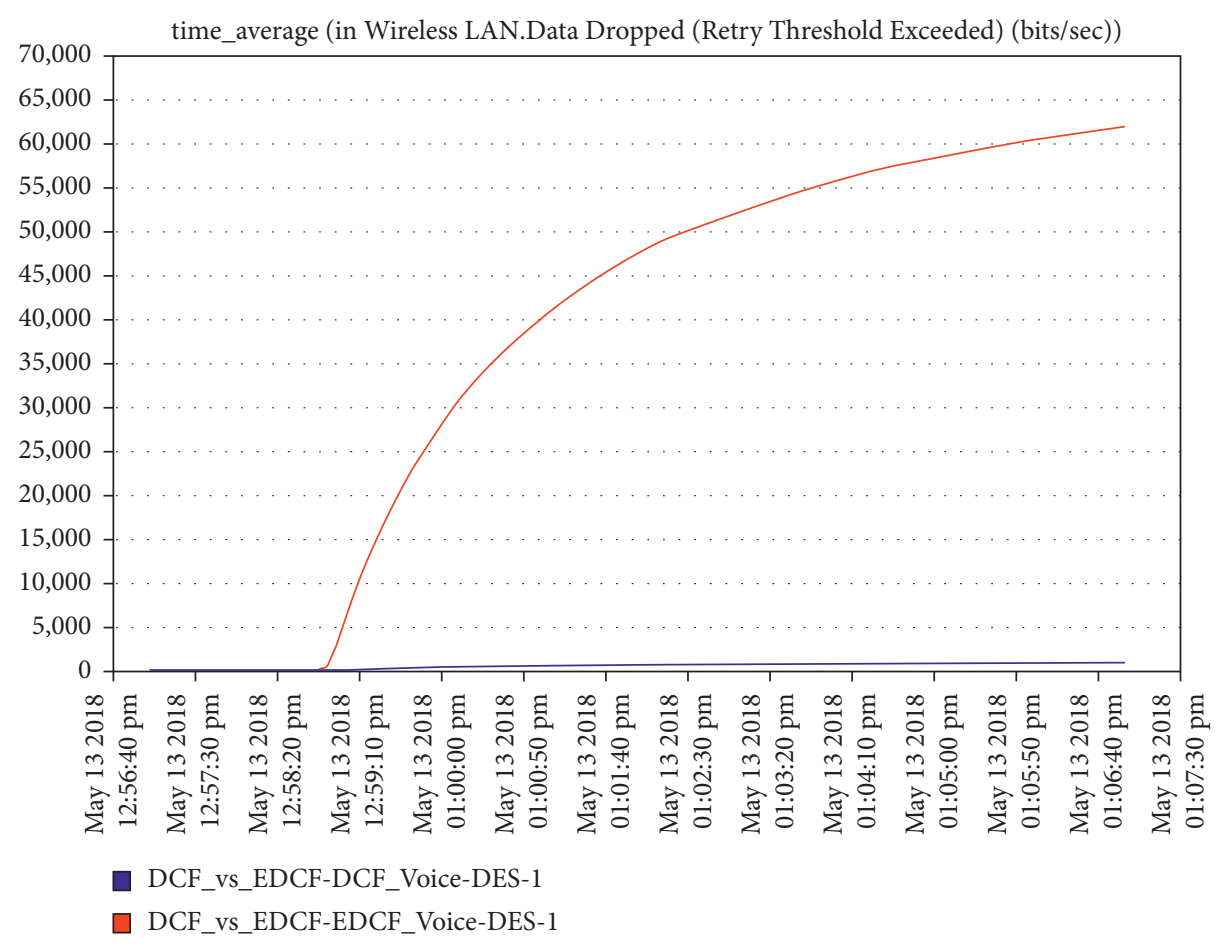

FIgURE 13: The data dropped in voice in mobility.

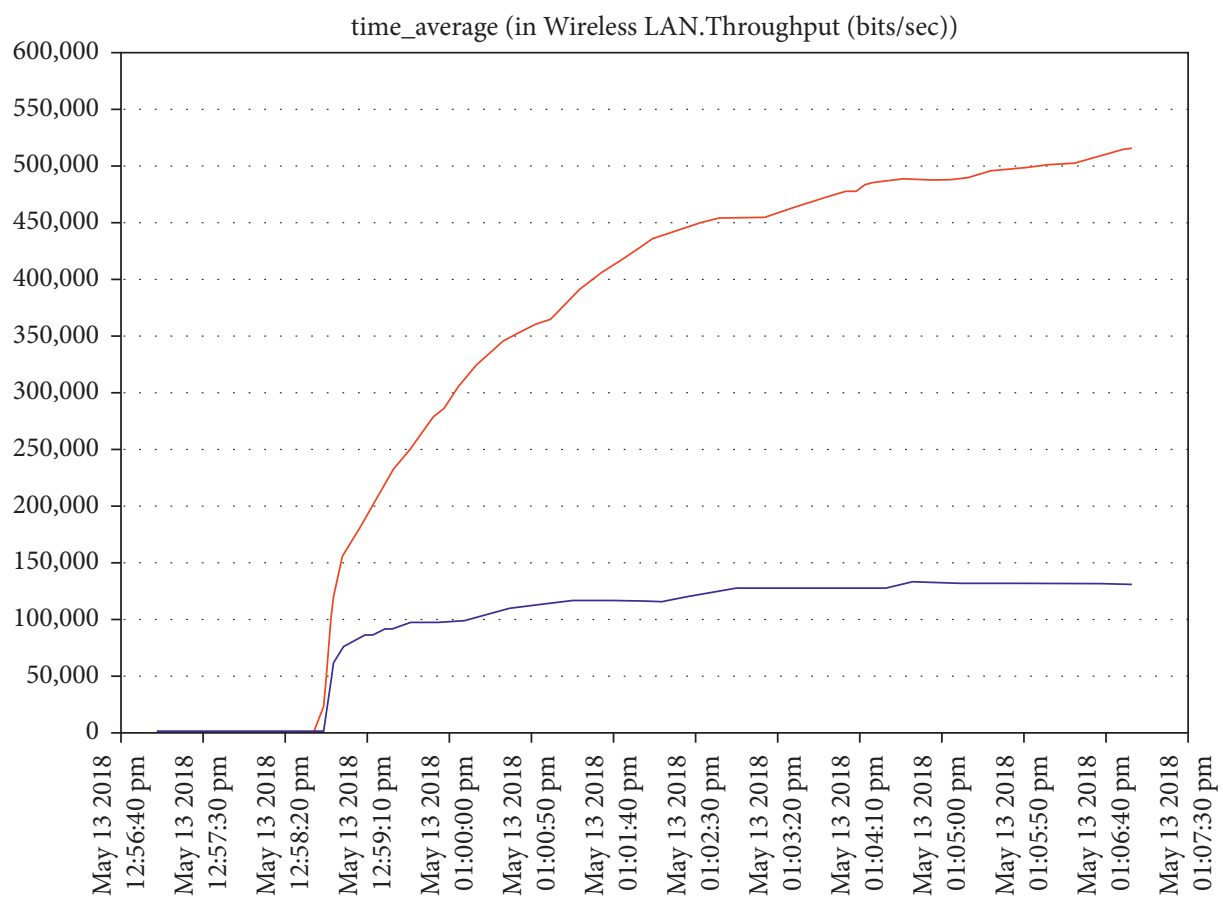

DCF_vs_EDCF-DCF_Video-DES-1

$\square$ DCF_vs_EDCF-EDCF_Video-DES-1

FIgURE 14: The throughput for video in mobility. 


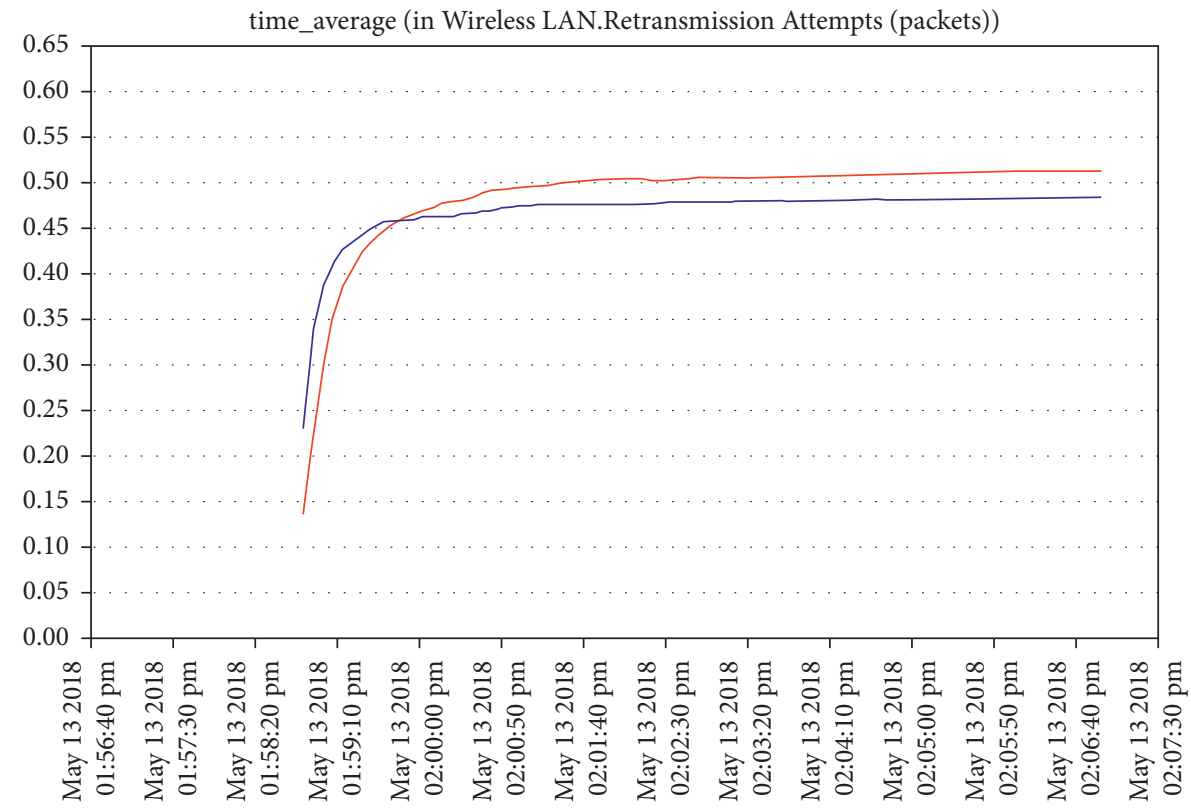

DCF_vs_EDCF-DCF_Video-DES-1

DCF_vs_EDCF-EDCF_Video-DES-1

FIgURE 15: Retransmission attempt in the video.

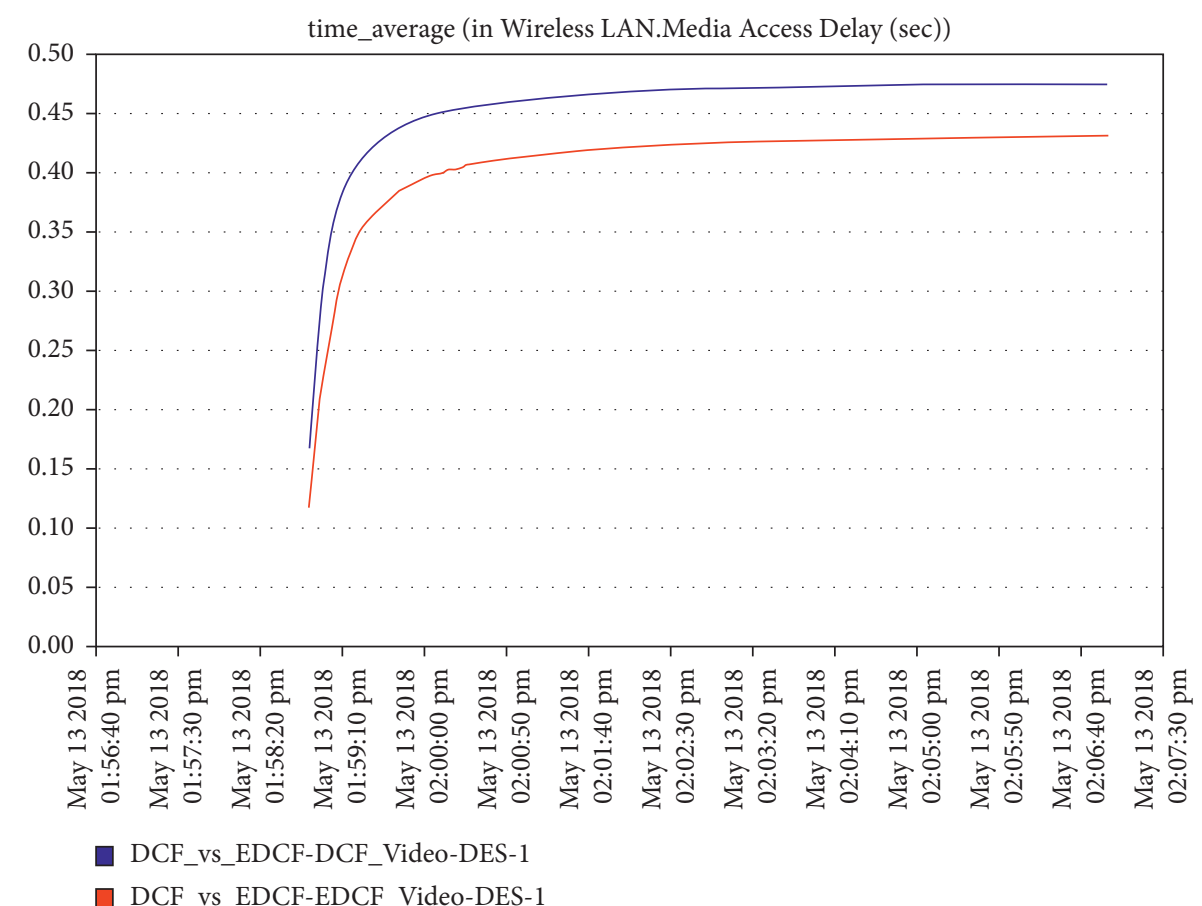

FIgURE 16: Media access delay in the video in mobility. 


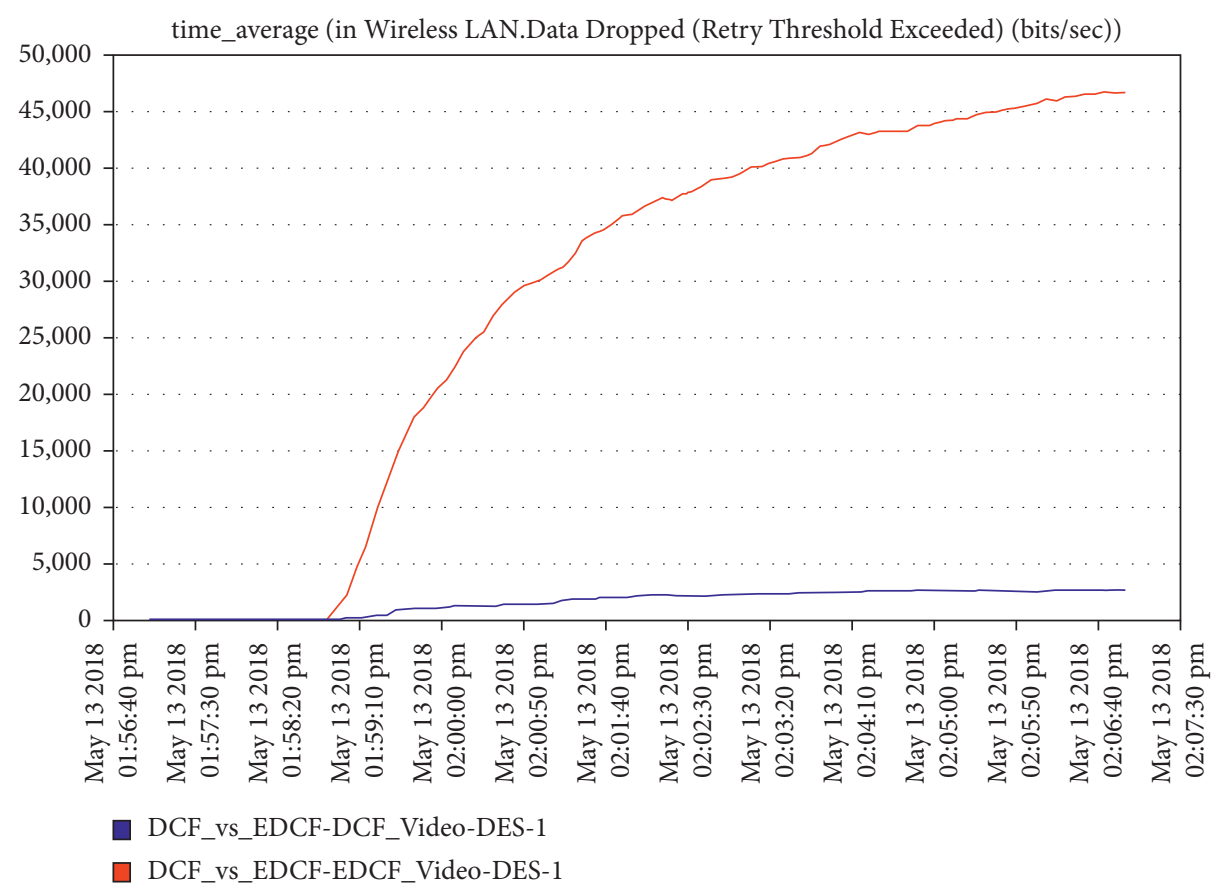

Figure 17: The data dropped in the video.

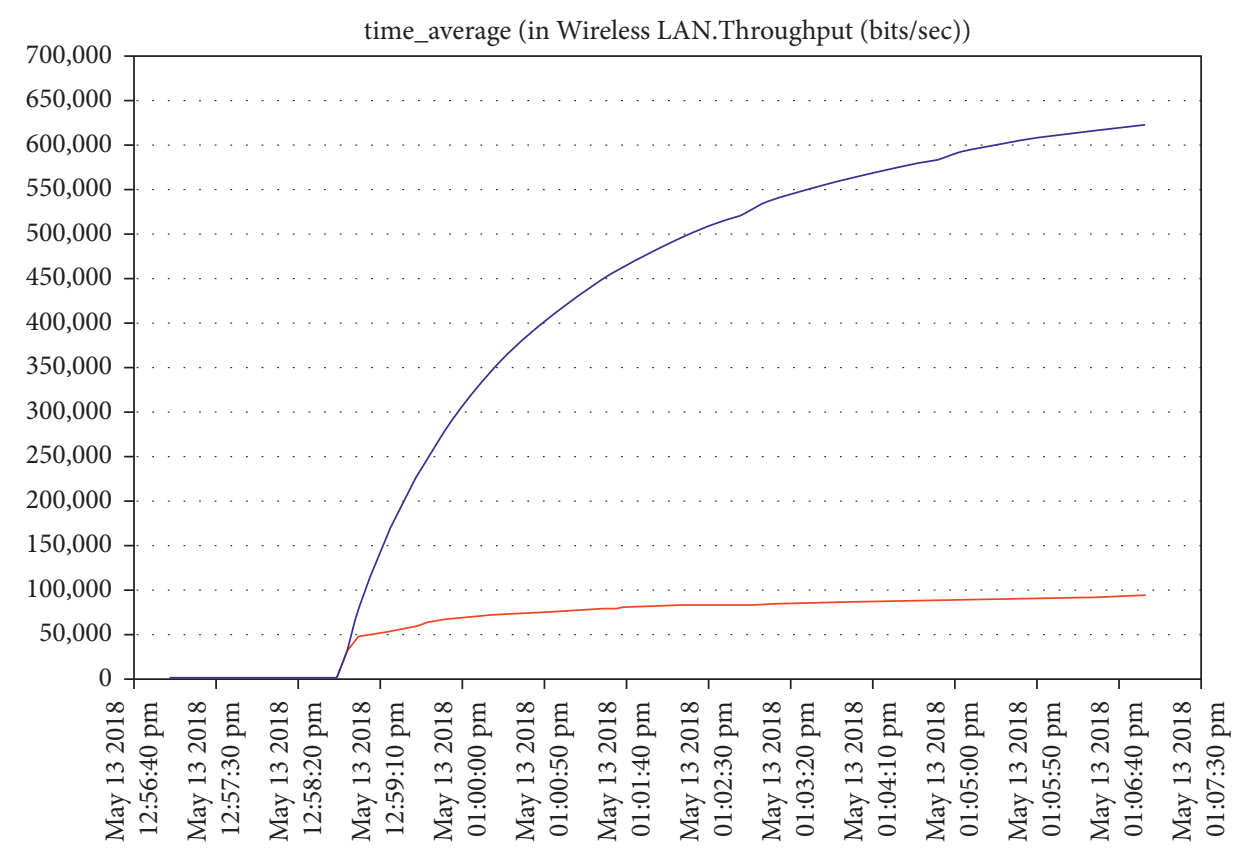

DCF_vs_EDCF-DCF_Voice-DES-1

$\square$ DCF_vs_EDCF-EDCF_Voice-DES-1

Figure 18: The throughput of voice. 


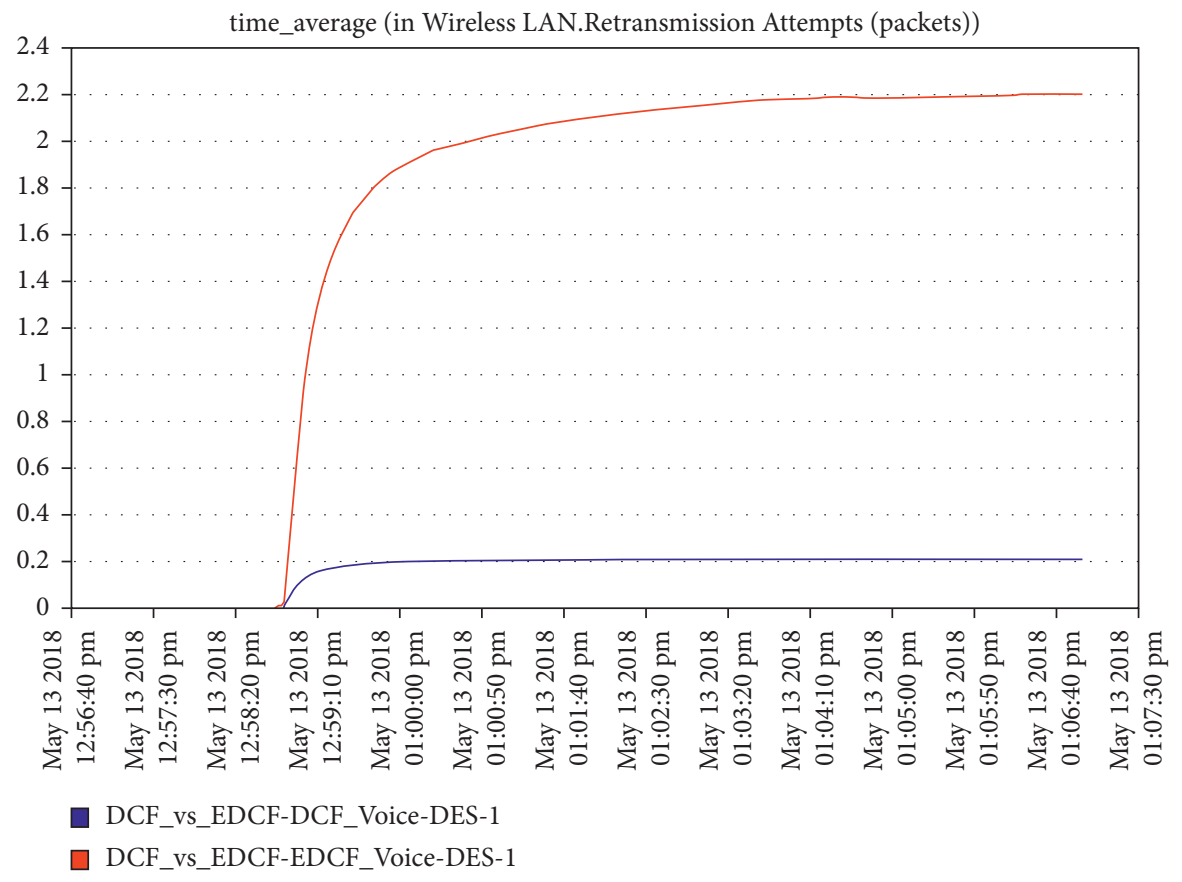

FIgURe 19: Retransmission attempt for voice.

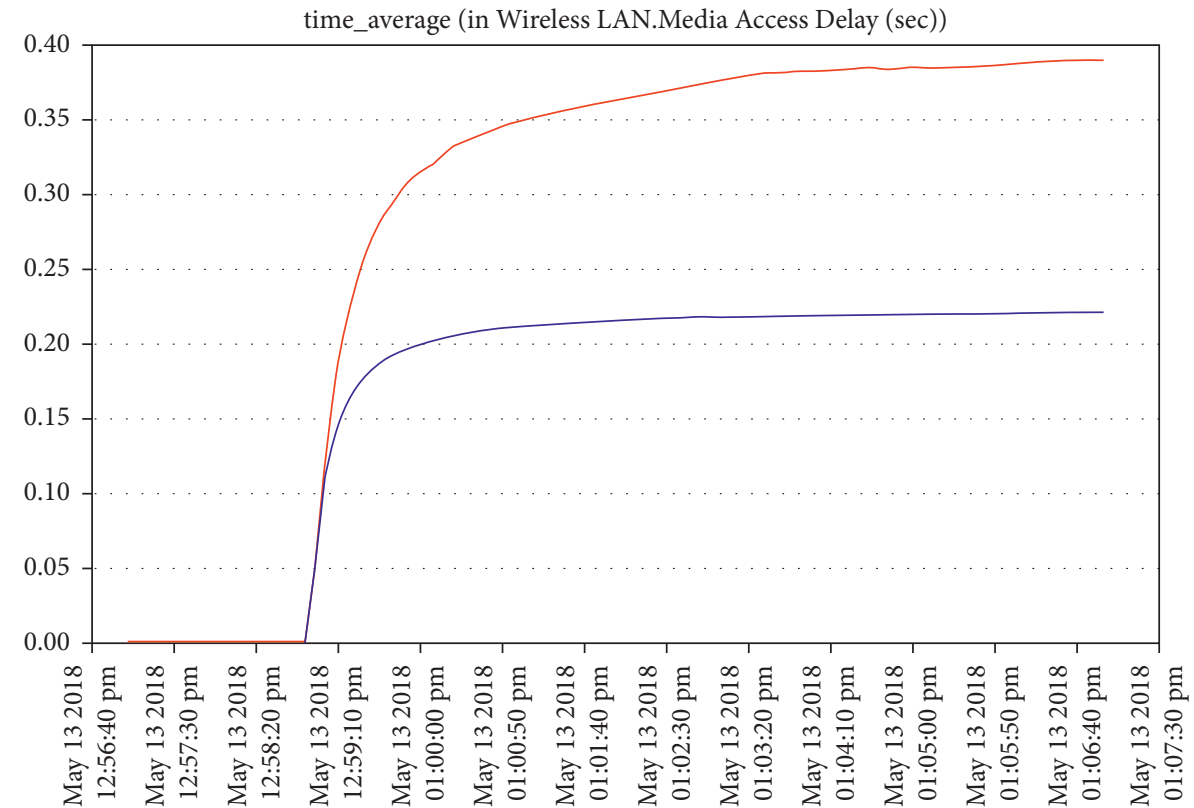

DCF_vs_EDCF-DCF_Voice-DES-1

$\square$ DCF_vs_EDCF-EDCF_Voice-DES-1

Figure 20: Media access delay for voice. 


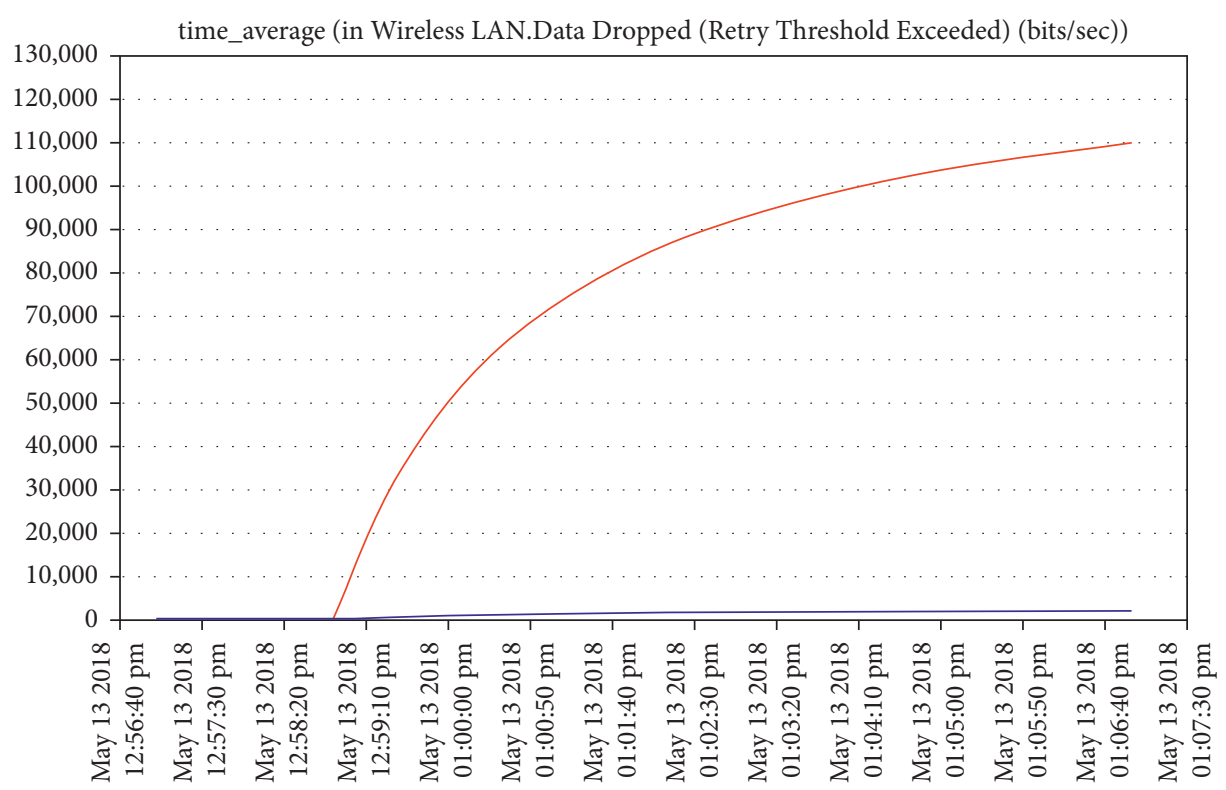

DCF_vs_EDCF-DCF_Voice-DES-1

$\square$ DCF_vs_EDCF-EDCF_Voice-DES-1

Figure 21: Data drop for voice.

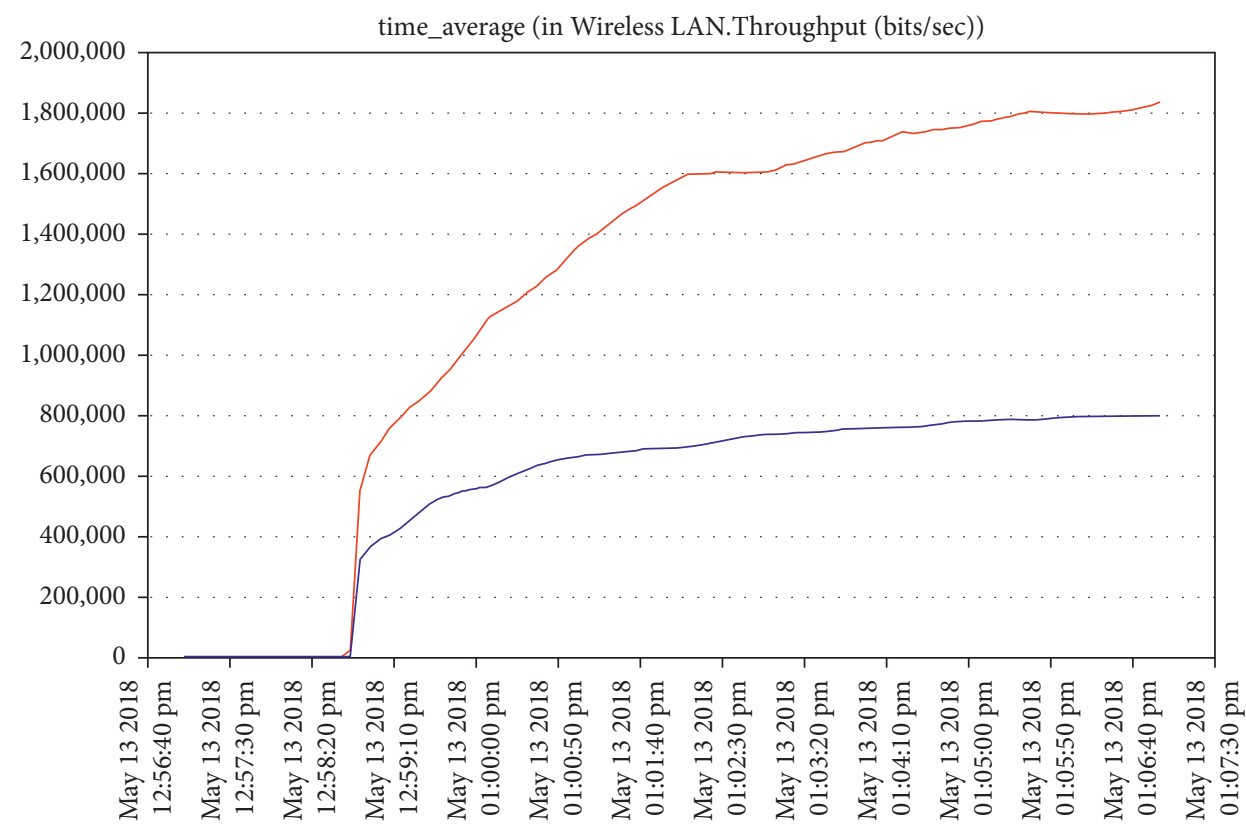

DCF_vs_EDCF-DCF_Video-DES-1

DCF_vs_EDCF-EDCF_Video-DES-1

FIgURE 22: Throughput for voice. 


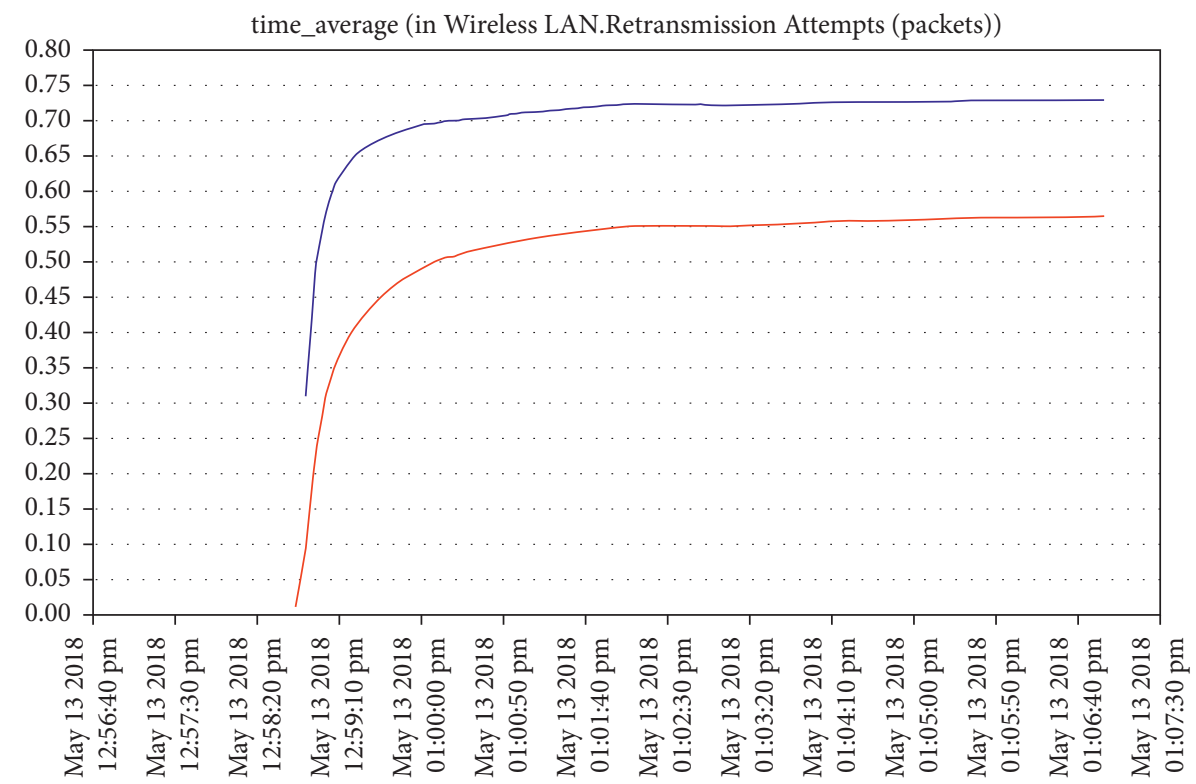

口 DCF_vs_EDCF-DCF_Video-DES-1

$\square$ DCF_vs_EDCF-EDCF_Video-DES-1

Figure 23: Retransmission attempts for video.

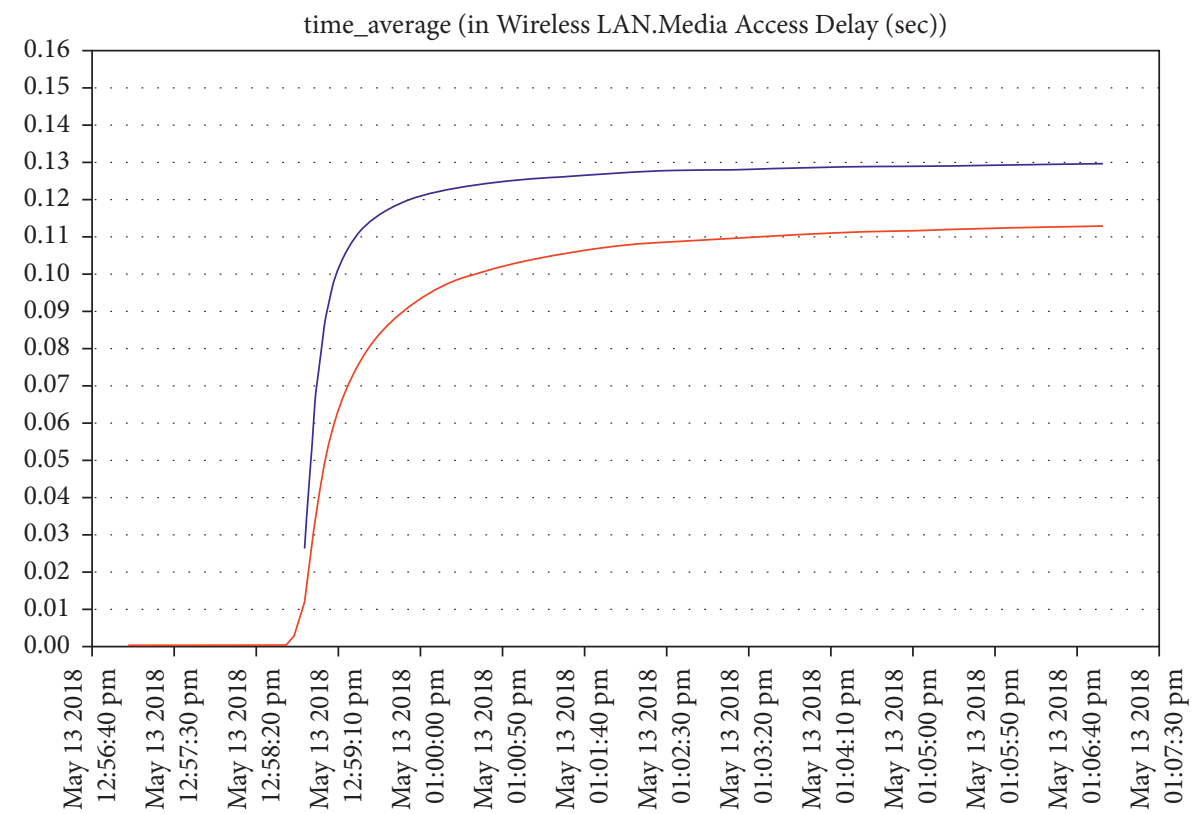

口DCF_vs_EDCF-DCF_Video-DES-1

$\square$ DCF_vs_EDCF-EDCF_Video-DES-1

Figure 24: Video media access delay. 


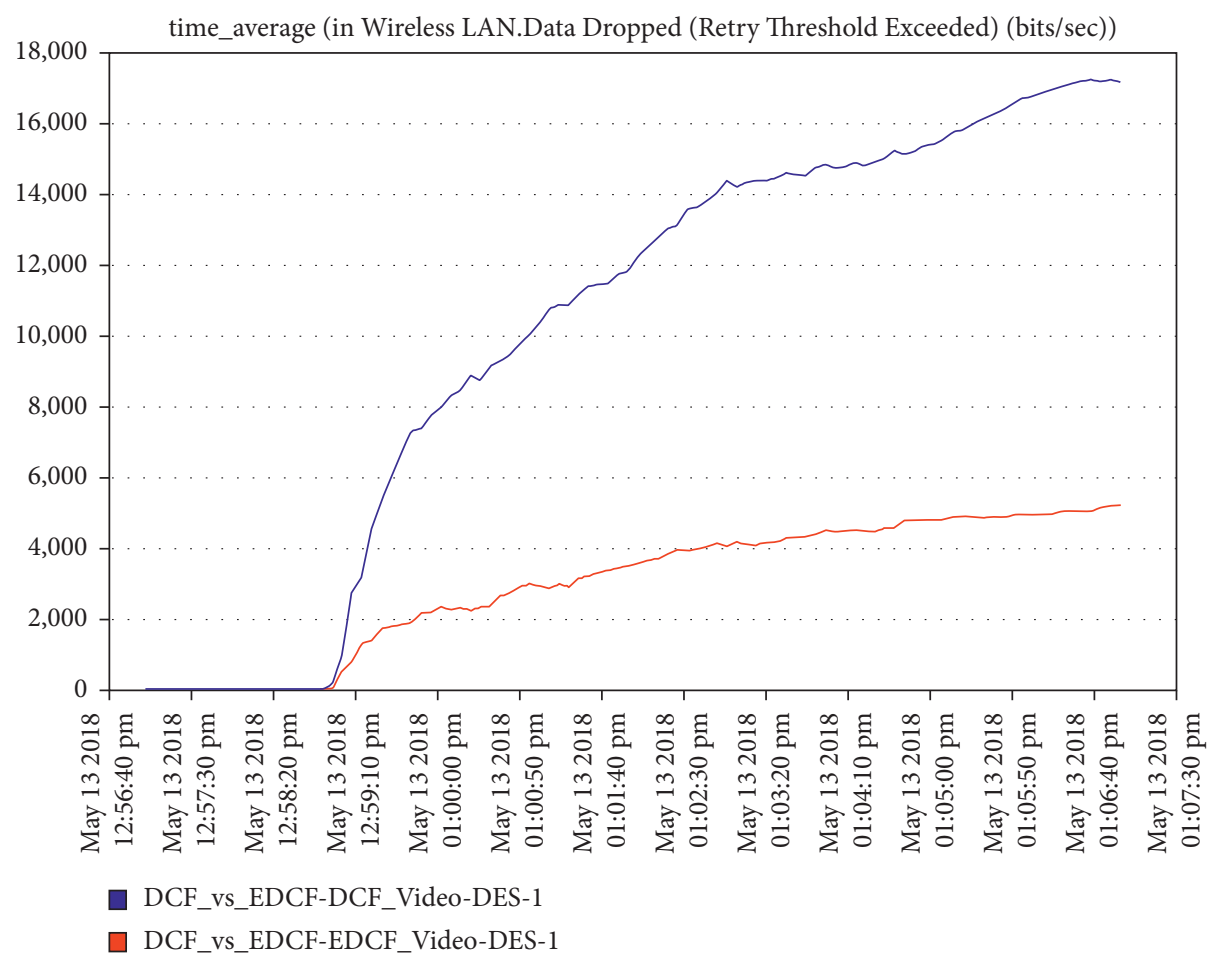

FIgURE 25: Data drop for real-time application, that is, video streamings.

\section{Conclusions}

Wireless local area networks recently get much interest among industry and academia researchers where many standards are coming out very fast. This fast grows results from a raised of the weaknessesofWLAN real-time applications quality that leads the nodes locked to deadlock or starvations. The future directions and challenges for 6G-enabled wireless communication for IoT applications are mainly focusing on the quality of services (QoS). The allocating of channel radios in WLAN for the higher needs activities is much more effective than for lower needs. Higher requirement activities made lower need activities that can be tolerated acceptable QoS. In terms of by and large execution (i.e., beneath the utilized recreation circumstances in the specific deliberate of QoS for WLAN), EDCF performs possibly less than DCF. This occurs because in EDCF nodes, all ACs perform like virtual systems and devices for media, so more packet collisions may be anticipated for EDCF situations.

The paper proposed a new QoS structure for the PCF that is based on an intelligent enhanced DCF that suites with dynamic RT IoT applications and services for the smart city, that is, RT surveillances, unmanned transportations and vehicles, smart management system for energy, city control, and monitoring rooms for environmental and security. In terms of quality of service (QoS) for real-time applications (i.e., video streaming or teleconferences), EDCF outperforms DCF. EDCFs frames have been aimed at the intelligent medium access control (IMAC) convention for IEEE standards growth and QoS standard IEEE802.11e. The remote gadgets utilizing
EDCF as intelligent IoT WLAN MAC convention would be accessible in the showcase within another coming two long times. By and by, all remote devices, DCF is utilized as the default medium access protocol, and PCFS frames are utilized as the discretionary usefulness. For future work, it is recommended to check the performance with different values of nodes and access points, for example, thirty, fourth, fifty, ... and so on. Additionally,it is recommended to applythe proposed technique to a different technologies, i.e., ad hoc, wireless sensor network. This paper has evaluated and tested through a large scale of the network of wireless nodes, and the throughput has been calculated utilizing $\mathrm{OPNET}^{\circledR}{ }^{\circledR}$ event-driven tool for network evaluation. The paper was modeled with limitations from different parameters and conditions such as the simulation tools limitation, simulation time, and limitations based on the microsystems memory and microprocessor used for running the OPNET ${ }^{\circledR}$. The proposed ECDF algorithm can still be enhanced with less delay, packet drop, and throughput.

\section{Data Availability}

The data sets or codes generated during and/or analyzed during the current study are available from the corresponding author on reasonable request.

\section{Conflicts of Interest}

The authors declare that they have no known competing financial interests or personal relationships that could have appeared to influence the work reported in this paper. 


\section{Acknowledgments}

This research was supported by Taif University Researchers Supporting Project (number: TURSP-2020/216), Taif University, Taif, Saudi Arabia.

\section{References}

[1] V. Sharma, H. Singh, and J. Malhotra, "Performance Analysis of IEEE 802.11e (EDCF) and IEEE 802.11(DCF) WLAN Incorporating Different Physical Layer Standards," Journal of the Institution of Engineers: Serie Bibliographique, vol. 93, no. 4, pp. 247-253, 2012.

[2] J. Singh and V. P. Singh, Quality of service in wireless LAN using OPNET modeler, Ph.D. dissertation, Computer Science and Engineering Department Thapar University, Patiala, Punjab, India, 2009.

[3] F. Alsolami, F. A. Alqurashi, M. K. Hasan, R. A. Saeed, S. Abdel-Khalek, and A. Ben Ishak, "Development of selfsynchronized drones' network using cluster-based swarm intelligence approach," IEEE Access, vol. 9, pp. 48010-48022, 2021.

[4] A. Mahanti, C. Williamson, and M. Arlitt, "Remote analysis of a distributed WLAN using passive wireless-side measurement," Performance Evaluation, vol. 64, pp. 9-12, 2007.

[5] L. F. Hussien, A. H. Aisha-Hassan, F. Anwar, O. Mahmoud, O. Zakaria, and R. A. Saeed, "Design of robust protocol to enhance QoS in mobile IPV6 environment," in Proceedings of the International Conference on Computer and Communication Engineering (ICCCE'10), pp. 1-5, Kuala Lumpur, Malaysia, May 2010.

[6] IEEE 802.11b-1999, IEEE Standard For Local And Metropolitan Area Networks Specific Requirements - Part 11: Wireless LAN Medium Access Control (MAC) And Physical Layer (PHY) Specifications High-Speed Physical Layer Extension In The 2.4 Ghz Band, IEEE, 1999.

[7] M. B. Hassan, S. Alsharif, H. Alhumyani, E. S. Ali, R. A. Mokhtar, and R. A. Saeed, "An enhanced cooperative communication scheme for physical uplink shared channel in NB-IoT," Wireless Personal Communications, vol. 120, no. 3, pp. 2367-2386, 2021.

[8] A. A. Eltahir, R. A. Saeed, A. Mukherjee, and M. K. Hasan, "Evaluation and analysis of an enhanced hybrid wireless mesh protocol for vehicular ad hoc network," EURASIP Journal on Wireless Communications and Networking, vol. 2016, no. 1, pp. 1-11, 2016.

[9] S. Song and B. Issac, "Analysis of WiFi and WiMax and wireless network coexistence," International journal of Computer Networks \& Communications, vol. 6, no. 6, 2014.

[10] D. J. Leith and P. Clifford, "Using the 802.11e EDCF to achieve TCP upload fairness over WLAN links," in Proceedings of the 3rd International Symposium on Modeling and Optimization in Mobile, Ad Hoc, and Wireless Networks 2004 (WiOPT '05), pp. 109-118, Trentino, Italy, April 2005.

[11] F. Zhao, "Comparison of analytical and measured performance results on network coding in IEEE 802.11 ad-hoc networks," in Proceedings of the 2012 International Symposium on Network Coding (NetCod), IEEE, Cambridge, MA, USA, June 2012.

[12] H. Hua Zhu, M. Ming Li, I. Chlamtac, and B. Prabhakaran, "A survey of quality of service in IEEE 802.11 networks," IEEE Wireless Communications, vol. 11, no. 4, pp. 6-14, 2004.
[13] D. Jinyun Zhang and J. Zhang, "QoS enhancement in IEEE802.11 wireless local area networks," IEEE Communications Magazine, vol. 41, no. 6, pp. 120-124, 2003.

[14] B. Bellalta, L. Bononi, R. Bruno, and A. Kassler, "Next generation IEEE 802.11 Wireless Local Area Networks: current status, future directions and open challenges," Computer Communications, vol. 75, pp. 1-25, 2016.

[15] S. Fluhrer, I. Mantin, and A. Shamir, "Weaknesses in the key scheduling algorithm of RC4," Selected Areas in Cryptography in Proceedings of the Springer Eighth Annual Workshop on Selected Areas in Cryptography 2001 (SAC '01), vol. 2259, pp. 1-24, Toronto, Canada, August 2001.

[16] M. S. Kuran and T. Tugcu, "A survey on emerging broadband wireless access technologies," Computer Networks, vol. 51, no. 11, pp. 3013-3046, 2007.

[17] A. A. Eltahir, R. A. Saeed, and M. A. Alawi, "An enhanced hybrid wireless mesh protocol (E-HWMP) protocol for multihop vehicular communications," in Proceedings of the 2013 International Conference on Computing, Electrical and Electronic Engineering (Icceee), pp. 1-8, Khartoum, Sudan, August 2013.

[18] IEEE, 802.11k-IEEE Standard for Information TechnologyLocal and Metropolitan Area Networks-specific RequirementsPart 11: Wireless LAN Medium Access Control (MAC) and Physica Layer (PHY) Specifications Amendment 1: Radio Resource Measurement of Wireless LANs, IEEE, Piscataway, NJ, USA, 2008.

[19] N. Nurelmadina, M. K. Hasan, I. Memon et al., "A systematic review on cognitive radio in low power wide area network for industrial IoT applications," MDPI, Sustainability, 2021.

[20] A. Šljivo, "Performance evaluation of IEEE 802.11ah networks with high-throughput bidirectional traffic," Sensors, vol. 18, p. $325,2018$.

[21] E. Perahia, "IEEE $802.11 \mathrm{n}$ development: history, process, and technology," Communications Magazine, IEEE, vol. 46, pp. $48-55,2008$.

[22] C. Casetti and C. Chiasserini, "Improving fairness and throughput for voice traffic in 802.11e EDCA," in Proceedings of the 2004 IEEE 15th International Symposium on Personal, Indoor and Mobile Radio Communications (IEEE Cat. No.04TH8754), vol. 1, pp. 525-530, Barcelona, Spain, 2004.

[23] Z. E. Ahmed, H. Kamrul, R. A. Saeed et al., "Optimizing energy consumption for cloud internet of things," Frontiers in Physics, vol. 8, 2020.

[24] S. Choi, S. Del, and S. Mangold, "IEEE 802.11 e contentionbased channel access (EDCF) performance evaluation," IEEE International Conference on Communications, vol. 2, pp. 1151-1156, 2003.

[25] S. N. Ghorpade, M. Zennaro, B. S. Chaudhari, RA. Saeed, H. Alhumyani, and S. Abdel-Khaled, "Enhanced differential crossover and quantum particle swarm optimization for IoT applications," IEEE Access, 2021.

[26] M. Ruhul Amin, "In-band full-duplex wireless LANs: medium access control protocols, design issues, and their challenges," Information, vol. 11, p. 216, 2020.

[27] L. Sanabria, "A high-efficiency MAC protocol for WLANs: providing fairness in dense scenarios,” 2015, https://arxiv.org/ pdf/1412.1395.pdf.

[28] S. Choi, J. D. Prado, and S. Mangold, "IEEE 802.11 e contention-based channel access (EDCF) performance evaluation," in Proceedings of the IEEE International Conference on In Communications, 2003. ICC'03, vol. 2, pp. 1151-1156, IEEE, May 2003. 
[29] M. B. Hassan, S. Alsharif, and H. Alhumyani, "An enhanced cooperative communication scheme for physical uplink shared channel in NB-IoT," Wireless Personal Communications, vol. 120, pp. 2367-2386, Anchorage, AK, USA, 2021.

[30] G. R. Hiertz, D. Denteneer, S. Max et al., "IEEE 802.11 s: the WLAN mesh standard," IEEE Wireless Communications, vol. 17, p. 1, 2010.

[31] L. Yang, P. Zerfos, and E. Sadot, Architecture Taxonomy for Control and Provisioning of Wireless Access Points (CAPWAP). No. RFC 4118, 2005.

[32] Z. Gál, A. Karsai, and P. Orosz, "Evaluation of IPv6 services in mobile WiFi environment," Computer Graphics, pp. 231-242, 2005.

[33] D. Deng, S. Lien, J. Lee, and K. Chen, "On quality-of-service provisioning in IEEE 802.11ax WLANs," IEEE Access, vol. 4, pp. 6086-6104, 2016.

[34] R. O. LaMaire1y, A. Krishnay, P. James, and P. Bhagwaty, "Wireless LANS and mobile networking: standards and future directions," IEEE, vol. 34, no. 8, 1996.

[35] D. A. Westcott, D. D. Coleman, B. Miller, and P. Mackenzie, CWAP Certified Wireless Analysis Professional Official Study Guide: Exam PW0-270, John Wiley \& Sons, New Jersey, NJ, USA, 2011.

[36] S. M. Faccin, W. Carl, J. Kenckt, and A. Damle, "Mesh WLAN networks: concept and system design," IEEE Wireless Communications, vol. 13, no. 2, pp. 10-17, 2006.

[37] A. Mishra, M. Shin, and W. Arbaugh, "An empirical analysis of the IEEE 802.11 MAC layer handoff process," ACM SIGCOMM - Computer Communication Review, vol. 33, no. 2, pp. 93-102, 2003.

[38] A. A. Eltahir and RA. Saeed, "Performance evaluation of an enhanced hybrid wireless mesh protocol (E-HWMP) protocol for VANET," in Proceedings of the International Conference on Computing, Control, Networking, Electronics and Embedded Systems Engineering (ICCNEEE), pp. 95-100, Khartoum, Sudan, September 2015.

[39] D. Cook and S. K. Das, Smart Environments: Technology, Protocols, And Applications, Vol. 43, John Wiley \& Sons, New Jersey, NJ, USA, 2004.

[40] M. Abdelgadir and R. A. Saeed, "Evaluation of performance enhancement of OFDM based on cross-layer design (CLD) IEEE 802.11p standard for vehicular ad-hoc networks (VANETs), city scenario," International Journal of Signal Processing Systems, vol. 8, no. 1, pp. 1-7, 2020.

[41] R. Bruno, M. Conti, and E. Gregori, "Mesh networks: commodity multihop ad hoc networks," IEEE Communications Magazine, vol. 43, no. 3, pp. 123-131, 2005.

[42] I. F. Akyildiz, W. Su, Y. Sankarasubramaniam, and E. Cayirci, "A survey on sensor networks," IEEE Communications Magazine, vol. 40, no. 8, pp. 102-114, 2002.

[43] B. Karp and H.-T. Kung, "GPSR: greedy perimeter stateless routing for wireless networks," in Proceedings of the 6th Annual International Conference on Mobile Computing and Networking, pp. 243-254, ACM, Boston, MA, USA, August 2000.

[44] B. E. Henty, A Brief Tutorial on the PHY and MAC Layers of the IEEE 802.11 B Standard, White paper, Intersil, 2001.

[45] C. Chaudet, D. Dhoutaut, and I. G. Lassous, "Performance issues with IEEE 802.11 in ad hoc networking," IEEE Communications Magazine, vol. 43, no. 7, pp. 110-116, 2005.

[46] V. A. Dubendorf, Wireless Data Technologies, John Wiley \& Sons, New Jersey, NJ, USA, 2003.

[47] K. Xu, Q. Wang, and H. Hassanein, "Performance analysis of differentiated QoS in IEEE 802.11 e WLANs," International
Journal of Communication Systems, vol. 18, no. 7, pp. 619-637, 2005.

[48] J. Singh and J. Singh, "Comparative analysis of PCF, DCF, and EDCF over IEEE 802.11 WLANs," International Journal of Advance research, Ideas and Innovations in Technology, vol. 2, 2016. 